\title{
The Cancer Chemotherapeutic Paclitaxel Increases Human and Rodent Sensory Neuron Responses to TRPV1 by Activation of TLR4
}

\author{
Yan Li, ${ }^{1}$ Pavel Adamek, ${ }^{4}$ Haijun Zhang, ${ }^{5}$ Claudio Esteves Tatsui, ${ }^{2}$ Laurence D. Rhines, ${ }^{2}$ Petra Mrozkova, ${ }^{4}$ Qin Li, ${ }^{3}$ \\ Alyssa K. Kosturakis, ${ }^{6}$ Ryan M. Cassidy, ${ }^{7}$ Daniel S. Harrison, ${ }^{8}$ Juan P. Cata, ${ }^{3}$ Kenneth Sapire, ${ }^{3}$ Hongmei Zhang, ${ }^{1}$ \\ Ross M. Kennamer-Chapman, ${ }^{7}$ Abdul Basit Jawad, ${ }^{7}$ Andre Ghetti, ${ }^{9}$ Jiusheng Yan, ${ }^{3}$ Jiri Palecek, ${ }^{4}$ \\ and Patrick M. Dougherty ${ }^{1}$ \\ Departments of ${ }^{1}$ Anesthesia and Pain Medicine, ${ }^{2}$ Neurosurgery, and ${ }^{3}$ Anesthesiology and Perioperative Medicine, The University of Texas M.D. Anderson \\ Cancer Center, Houston, Texas 77030, ${ }^{4}$ Department of Functional Morphology, Institute of Physiology, Academy of Sciences Czech Republic, 14220 Prague, \\ Czech Republic, ${ }^{5}$ Department of Anesthesiology, University of Texas Medical School at Houston, Houston, Texas 77030, ${ }^{6}$ University of Texas Health Science \\ Center, San Antonio, Texas 78229, ${ }^{7}$ University of Texas Health Science Center, Houston, Texas 77030, ${ }^{8}$ Duke University School of Medicine, Durham, North \\ Carolina 27710, and ${ }^{9}$ Anabios, Inc., San Diego, California 92109
}

Peripheral neuropathy is dose limiting in paclitaxel cancer chemotherapy and can result in both acute pain during treatment and chronic persistent pain in cancer survivors. The hypothesis tested was that paclitaxel produces these adverse effects at least in part by sensitizing transient receptor potential vanilloid subtype 1 (TRPV1) through Toll-like receptor 4 (TLR4) signaling. The data show that paclitaxelinduced behavioral hypersensitivity is prevented and reversed by spinal administration of a TRPV1 antagonist. The number of TRPV1 ${ }^{+}$ neurons is increased in the dorsal root ganglia (DRG) in paclitaxel-treated rats and is colocalized with TLR4 in rat and human DRG neurons. Cotreatment of rats with lipopolysaccharide from the photosynthetic bacterium Rhodobacter sphaeroides (LPS-RS), a TLR4 inhibitor, prevents the increase in numbers of TRPV ${ }^{+}$neurons by paclitaxel treatment. Perfusion of paclitaxel or the archetypal TLR 4 agonist LPS activated both rat DRG and spinal neurons directly and produced acute sensitization of TRPV1 in both groups of cells via a TLR4-mediated mechanism. Paclitaxel and LPS sensitize TRPV1 in HEK293 cells stably expressing human TLR4 and transiently expressing human TRPV1. These physiological effects also are prevented by LPS-RS. Finally, paclitaxel activates and sensitizes TRPV1 responses directly in dissociated human DRG neurons. In summary, TLR4 was activated by paclitaxel and led to sensitization of TRPV1. This mechanism could contribute to paclitaxel-induced acute pain and chronic painful neuropathy.

Key words: cancer; dorsal horn; DRG; neuropathy

Significance Statement

In this original work, it is shown for the first time that paclitaxel activates peripheral sensory and spinal neurons directly and sensitizes these cells to transient receptor potential vanilloid subtype 1 (TRPV1)-mediated capsaicin responses via Toll-like receptor 4 (TLR4) in multiple species. A direct functional interaction between TLR4 and TRPV1 is shown in rat and human dorsal root ganglion neurons, TLR4/TRPV1-coexpressing HEK293 cells, and in both rat and mouse spinal cord slices. Moreover, this is the first study to show that this interaction plays an important role in the generation of behavioral hypersensitivity in paclitaxelrelated neuropathy. The key translational implications are that TLR4 and TRPV1 antagonists may be useful in the prevention and treatment of chemotherapy-induced peripheral neuropathy in humans.

\section{Introduction}

Paclitaxel is the frontline chemotherapeutic agent used to treat many of the most common solid tumors (Hagiwara and Sunada,
2004). Peripheral neuropathy is the major dose-limiting adverse effect of paclitaxel and can force dose reduction or even discontinuation of therapy, thus affecting survival (Chaudhry et al., 
1994). Moreover, chemotherapy-induced peripheral neuropathy (CIPN) often becomes a chronic condition that is refractory to treatment, affecting rehabilitation, productivity, and quality of life in cancer survivors (Boyette-Davis et al., 2011b; BoyetteDavis et al., 2013; Kosturakis et al., 2014). In addition to the universal reports of numbness and near universal reports of tingling, the next most common symptoms experienced by CIPN patients is constant, burning pain or deep, aching pain (BoyetteDavis et al., 2011b; Boyette-Davis et al., 2013). In addition to chronic neuropathy, paclitaxel is also associated with an acute pain syndrome (Reeves et al., 2012). Like chronic CIPN, the paclitaxel acute pain syndrome is associated with the development of overt neuropathy and is characterized by patient complaints of deep muscle aches and arthralgia (Reeves et al., 2012). Also like chronic CIPN, there is no clear preventative treatment and the underlying mechanisms remain poorly defined.

Transient receptor potential vanilloid subtype 1 (TRPV1) has been widely studied in pain mechanisms. It is located on subsets of nociceptors and is activated by numerous stimuli that are perceived as painful or noxious, including capsaicin, the active ingredient in hot chili peppers, as well as by protons, heat $>42^{\circ} \mathrm{C}$, and a family of endogenous-inflammation-associated lipids (for review, see Nagy et al., 2014). The sensation evoked in humans by activation of TRPV1 in skin by capsaicin is burning (Simone et al., 1989); whereas, when applied into muscle, it is perceived as deep aching or cramping pain (Marchettini et al., 1996; Witting et al., 2000) matching the patient complaints associated with paclitaxel (Boyette-Davis et al., 2011b; Boyette-Davis et al., 2013). Consistent with these observations, TRPV1 expression is increased in rat dorsal root ganglia (DRG) by paclitaxel treatment when thermal hyperalgesia is observed and the use of a TRPV1 antagonist reduced this hypersensitivity (Hara et al., 2013).

Toll-like receptors (TLRs) play important roles in acute and chronic itch and pain (Christianson et al., 2011). Recent studies have demonstrated that TLR3 and TLR7 are expressed by a subset of primary sensory neurons that coexpress itch and pain signaling components, including TRPV1 (Liu et al., 2010; Liu et al., 2012). Another member of this family, TLR4, plays a key role in the transition of inflammatory pain to chronic status and in promoting the generation of nerve injury pain (Christianson et al., 2011; Stokes et al., 2013; Agalave et al., 2014). More recently, the expression and signaling of TLR4 was shown to be increased with paclitaxel treatment and cotreatment of rats with a TLR4 antagonist during chemotherapy prevented the development of the CIPN phenotype (Li et al., 2014b). Paclitaxel appears to engage TLR4 in the same fashion as its canonical, well known proinflammatory agonist lipopolysaccharide (LPS) (Han et al., 1994; Karin and Ben-Neriah, 2000; Byrd-Leifer et al., 2001; Byrd-Leifer et al., 2001; Li et al., 2013), resulting in the induction and release of the same proinflammatory cytokines from macrophages and other cells (O'Brien et al., 1995; Zaks-Zilberman et al., 2001). The same signaling cascade as in macrophages appears to be activated by paclitaxel in peripheral sensory neurons, resulting in downstream activation of the TLR4 adapter proteins MyD88-nuclear

This work was supported by the National Institutes of Health (Grants NS 046606 and CA016672), the H.E.B. Professorship in Cancer Research, and by the Granting Agency of the Czech Republic (Grants LH12058, CZ.1.07/ 2.3.00/30.0025, GACR 15-11138S, and RV067985823).

The authors declare no competing financial interests.

Correspondence should be addressed to Dr. PatrickM. Dougherty, Department of Pain Medicine, The University of Texas M.D. Anderson Cancer Center, 1515 Holcombe Blvd., Unit 110, Houston, TX 77030. E-mail pdougherty@mdanderson.org.

DOI:10.1523/JNEUROSCI.1956-15.2015

Copyright $\odot 2015$ the authors $\quad 0270-6474 / 15 / 3513488-14 \$ 15.00 / 0$ factor $-\kappa \mathrm{B} \quad(\mathrm{NF}-\kappa \mathrm{B})$ and TIR-domain-containing adapterinducing interferon- $\beta$ (TRIF) and the same mitogen-activated protein kinase (MAPK) signaling cascades ( $\mathrm{Li}$ et al., 2015). Finally, TLR4 and TRPV1 have been shown to be colocalized in human trigeminal ganglion neurons and posited to underlie infection-induced oral pain (Diogenes et al., 2011). The hypothesis tested here in mouse, rat, and human tissues is that DRG neurons coexpress TLR4 and TRPV1 and that paclitaxel activates TLR4 and sensitizes TRPV1, resulting in increased pain signaling that contributes to the generation of CIPN-related hyperalgesia.

\section{Materials and Methods}

Animals. All experimental animal protocols were approved by the Institutional Animal Care and Use Committee at The University of Texas M.D. Anderson Cancer Center or the Institute of Physiology, Czech Academy of Sciences, and were performed in accordance with the National Institutes of Health Guidelines for the Care and Use of Laboratory Animals. Every procedure was designed to minimize discomfort to the animals and to use the fewest animals needed for statistical analysis.

Male Sprague Dawley rats weighing 250-300 g (Harlan Laboratories) were used in the behavioral, pharmacological, immunohistochemistry, and Western blot experiments; 5-week-old rats were used in the sEPSC and DRG neurophysiology experiments. Male Wistar rats at postnatal day 21 (P21) to P23 and adult male C57BL/6 mice were used for the acute paclitaxel spinal cord slice neurophysiology experiments. All animals were housed in temperature- and light-controlled ( $12 \mathrm{~h}$ light/dark cycle) conditions with food and water available ad libitum. The specific numbers of animals used in each set of experiments are detailed in the relevant sections of the Results.

Paclitaxel treatment. Male Sprague Dawley rats were treated with paclitaxel (TEVA Pharmaceuticals) as described previously (Polomano et al., 2001; Boyette-Davis and Dougherty, 2011; Boyette-Davis et al., 2011a; Zhang et al., 2013a). In brief, pharmaceutical-grade Taxol was diluted with sterile saline from the original stock concentration of $6 \mathrm{mg} / \mathrm{ml}$ (in 1:1 Cremophor EL: ethanol) to $1 \mathrm{mg} / \mathrm{ml}$ and given at a dosage of $2 \mathrm{mg} / \mathrm{kg}$ intraperitoneally every other day for a total of 4 injections (days $0,2,4$, and 6), resulting in a final cumulative dose of $8 \mathrm{mg} / \mathrm{kg}$. Control animals received an equivalent volume of the vehicle only, which consisted of equal amounts of Cremophor EL and ethanol diluted with saline to reach the same concentration of vehicle as in the paclitaxel solution. No abnormal spontaneous behavioral changes were noted during or after paclitaxel or vehicle treatment.

TRPV1 and TLR4 antagonist intrathecal administration. The effects of the TRPV1 antagonist AMG9810 (Tocris Bioscience) and the TLR4 antagonist lipopolysaccharide from the photosynthetic bacterium Rhodobacter sphaeroides (LPS-RS) on paclitaxel-induced mechanical hypersensitivity were both tested after intrathecal injection. The rats were briefly anesthetized with $3 \%$ isoflurane, flexed over a tube, and a $27-$ gauge needle was inserted between the L5 and S1 vertebrae with a deflection of the tail indicating entry to the subarachnoid space. The dose of both agents were chosen based on previously published studies (Yu et al., 2008; Li et al., 2014b). AMG9810 was tested on both preestablished paclitaxel CIPN and as a preventative agent during chemotherapy. The first experiment was done at day 14 after paclitaxel treatment in rats with confirmed hyperalgesia. AMG9810 was given at a dose of $15 \mu \mathrm{g}$ in $20 \mu \mathrm{l}$ of PBS (InvivoGen); control rats received $20 \mu$ l of vehicle solution in PBS alone. In the second experiment, $15 \mu \mathrm{g}$ of AMG9810 was given in $20 \mu \mathrm{l}$ of PBS beginning $2 \mathrm{~d}$ before paclitaxel treatment and then daily through day 2 after paclitaxel treatment. LPS-RS $(20 \mu \mathrm{g}$ in $20 \mu \mathrm{l})$ was given using the same repeated dosing scheme beginning $2 \mathrm{~d}$ before paclitaxel treatment and then daily through last dose of paclitaxel treatment.

Mechanical withdrawal test. Mechanical withdrawal threshold was tested before, during, and after paclitaxel treatment by an experimenter blinded to treatment groups during the mid-light hours (10:00 A.M. to 5:00 P.M.). The $50 \%$ paw withdrawal threshold in response to a series of 8 von Frey hairs $(0.41-15.10 \mathrm{~g})$ was examined by the up-down method, as described previously (Chaplan et al., 1994), beginning with a filament with a bending force of $2.0 \mathrm{~g}$. Animals were placed under clear acrylic 
cages atop a wire mesh floor. The filaments were applied to the paw just below the pads with no acceleration at a force just sufficient to produce a bend and held for 6-8 s. A quick flick or full withdrawal was considered a response.

Immunohistochemical analysis. Rats were deeply anesthetized with sodium pentobarbital (Nembutal, $100 \mathrm{mg} / \mathrm{kg}$, i.p.; Lundbeck) and perfused through the ascending aorta with warm saline followed by cold $4 \%$ paraformaldehyde in $0.1 \mathrm{M}$ PB. The L4 and L5 DRG were removed, fixed in $4 \%$ paraformaldehyde for $6 \mathrm{~h}$, and then cryoprotected in 30\% sucrose solution. The L4 and L5 spinal cord segments were also removed, fixed in $4 \%$ paraformaldehyde for $12 \mathrm{~h}$, and then cryoprotected in $30 \%$ sucrose solution. Transverse spinal cord sections $(15 \mu \mathrm{m})$ and longitudinal DRG sections $(8 \mu \mathrm{m})$ were cut in a cryostat, mounted on gelatin-coated glass slides (Southern Biotech), and processed for immunofluorescent staining. After blocking in 5\% normal donkey serum and $0.2 \%$ Triton X-100 in PBS for $1 \mathrm{~h}$ at room temperature, the sections were incubated overnight at $4^{\circ} \mathrm{C}$ in $1 \%$ normal donkey serum and $0.2 \%$ Triton $\mathrm{X}-100$ in PBS containing primary antibodies against the following targets: TRPV1 (rabbit anti-rat, 1:1000; Alomone), TLR4 (mouse anti-rat, 1:200; Abcam), IB4 (1:1000 BS-Isolectin B4 FITC Conjugate; Sigma-Aldrich), and CGRP (mouse anti-rat, 1:1000; Abcam). After washing, the sections were then incubated with Cy3-, Cy5-, or FITC-conjugated secondary antibodies overnight at $4^{\circ} \mathrm{C}$. Sections were viewed under a fluorescent microscope with a $20 \times$ objective (Eclipse E600; Nikon) and images were collected using identical acquisition parameters by experimenters blinded to treatment groups. The total number of cells, their diameters, and the numbers with positive staining for TRPV1 and the numbers showing colocalization with IB4 or CGRP were counted from three sections of DRG from four rats.

Acute dissociation of rat DRG neurons. Rats were deeply anesthetized with isoflurane and the bilateral L4 and L5 ganglia were surgically exposed and removed. The ganglia were placed in a culture dish containing $1 \mathrm{ml}$ of trypsin $(0.125 \mathrm{mg} / \mathrm{ml}$; Hyclone $)$ and $1 \mathrm{ml}$ of type IA collagenase ( 2 $\mathrm{mg} / \mathrm{ml}$; Sigma-Aldrich) in DMEM. The dish was shaken for $50 \mathrm{~min}$ in a heated $\left(37^{\circ} \mathrm{C}\right)$ chamber. After the cells were washed and mechanically dispersed with a polished Pasteur pipette, they were plated on poly-Lornithine-coated glass sheets and held in culture dishes with DMEM until use ( $\mathrm{Li}$ et al., 2014a). The cells were used for calcium imaging or patch clamp within $6 \mathrm{~h}$ after plating.

Intracellular calcium imaging in acutely dissociated DRG neurons. Cells were transferred from the culture dishes to a bath with oxygenated ( $95 \%$ $\mathrm{O}_{2}+5 \% \mathrm{CO}_{2}$ ) artificial CSF (ACSF) solution that contained the ratio metric $\mathrm{Ca}^{2+}$ indicator dye Fura-2AM ( $2 \mu \mathrm{M}$; Invitrogen) and allowed to incubate for at least $30 \mathrm{~min}$ at $37^{\circ} \mathrm{C}$ before use as described previously (Zhang et al., 2013a). The ACSF solution contained the following (in $\mathrm{mm}$ ): $117.0 \mathrm{NaCl}, 3.6 \mathrm{KCl}, 1.2 \mathrm{MgCl}_{2}, 1.5 \mathrm{CaCl}_{2}, 1.2 \mathrm{NaH}_{2} \mathrm{PO}_{4}, 11.0$ glucose, and $25.0 \mathrm{NaHCO}_{3}$. The cells were then transferred to a recording chamber placed on an inverted microscope (Eclipse Ti; Nikon) and perfused with oxygenated ACSF $(2 \mathrm{ml} / \mathrm{min}$ ) at room temperature. The intracellular calcium concentration was expressed as the $340 / 380$ ratio and the signals were captured and analyzed with NIS-Elements AR software (Nikon). All chemicals were applied directly into the bath.

Whole-cell patch recording in acutely dissociated DRG neurons. Wholecell patch recording was performed as described previously (Li et al., 2014a). The cells were transferred to a recording chamber placed on an inverted microscope (Eclipse Ti; Nikon) and perfused with oxygenated $\operatorname{ACSF}(2 \mathrm{ml} / \mathrm{min})$ at room temperature. Only neurons with a stable resting membrane potential of at least $-40 \mathrm{mV}$ and evoked spikes that overshot $0 \mathrm{mV}$ were used. Series resistance was compensated to $>70 \%$.

Spinal cord slice preparation and electrophysiological recordings from adult paclitaxel/vehicle-treated rats. Sprague Dawley rats (5 weeks old) were anesthetized with $2-3 \%$ isoflurane and laminectomy was used to expose and remove the L3-L6 segments of the spinal cord (Zhang et al., 2010). The animals were then killed by inhalation of 5\% isoflurane and exsanguination. The spinal cord segments were immediately placed in ice-cold sucrose-ACSF saturated with $95 \% \mathrm{O}_{2}$ and $5 \% \mathrm{CO}_{2}$. The sucrose-ACSF solution contained the following (in $\mathrm{mm}$ ): 234 sucrose, 3.6 $\mathrm{KCl}, 1.2 \mathrm{MgCl}_{2}, 2.5 \mathrm{CaCl}_{2}, 1.2 \mathrm{NaH}_{2} \mathrm{PO}_{4}, 12.0$ glucose, and 25.0 $\mathrm{NaHCO}_{3}$. The tissue was then placed in a shallow groove formed in a gelatin block and glued onto the stage of a Vibratome (Products International). Transverse spinal cord slices $(300 \mu \mathrm{m})$ were cut in the ice-cold sucrose-ACSF and then transferred and incubated in regular ACSF bubbled with $95 \% \mathrm{O}_{2}$ and $5 \% \mathrm{CO}_{2}$ at $34^{\circ} \mathrm{C}$ for at least $1 \mathrm{~h}$ before further use.

Slices for study were placed in a glass-bottomed recording chamber (Warner Instruments) and fixed with parallel nylon threads supported by a U-shaped stainless-steel weight. The slice was perfused with ACSF at $2.0 \mathrm{ml} / \mathrm{min}$ at $34^{\circ} \mathrm{C}$ maintained by an inline solution heater and temperature controller (TC-344B; Warner Instruments).

Recordings of postsynaptic currents were performed using whole-cell voltage-clamp, as described previously (Zhang et al., 2010; Zhang et al., 2013b). All recordings were conducted in lamina II neurons at the L5 spinal level. Lamina II was identified by its distinctive translucent appearance and neurons were located with use of a fixed-stage microscope (BX51WI; Olympus) with differential interference contrast/infrared illumination. Electrodes for the whole-cell recordings were triple-pulled from borosilicate glass capillary tubes using a horizontal electrode puller (P-97; Sutter Instrument). The impedance of the pipette was 4-7 M $\Omega$ when filled with internal solution containing the following (in $\mathrm{mm}$ ): 135 K-gluconate, $5 \mathrm{KCl} ; 2.0 \mathrm{MgCl}_{2}, 0.5 \mathrm{CaCl}_{2}$, 5.0 HEPES, 5.0 EGTA, 5.0 ATP-Mg, and 0.5 Na-GTP adjusted to $\mathrm{pH} 7.2-7.4$ with $1 \mathrm{M} \mathrm{KOH} \mathrm{(290-}$ $320 \mathrm{mOsm}$ ). Recordings of postsynaptic currents began $\sim 5 \mathrm{~min}$ after whole-cell access was established and the current had reached a steady state. Input resistance was monitored and recording was abandoned if this changed by $>15 \%$. Signals were amplified by using a MultiClamp700B (Molecular Devices) at a holding potential of $-70 \mathrm{mV}$ for sEPSC, filtered at 2 $\mathrm{kHz}$, digitized at $10 \mathrm{kHz}$ (Digidata 1322A; Molecular Devices), and stored on a personal computer for later analysis.

Spinal cord slice preparation from juvenile Wistar rats and adult C57BL/6 mice. Acute spinal cord slices were prepared from male Wistar rats on P21-P23 and from adult male C57BL/6 mice weighing 25-30 g using the same methods as in the adult rats, but with some minor differences in the solutions for improved stability in these tissues. The dissection solution contained the following (in $\mathrm{mM}$ ): $95 \mathrm{NaCl}, 1.8 \mathrm{KCl}, 7$ $\mathrm{MgSO}_{4}, 0.5 \mathrm{CaCl}_{2}, 1.2 \mathrm{KH}_{2} \mathrm{PO}_{4}, 26 \mathrm{NaHCO}_{3}, 25$ D-glucose, and $50 \mathrm{su}$ crose. The ACSF for the recordings contained the following (in $\mathrm{mm}$ ): 127 $\mathrm{NaCl}, 1.8 \mathrm{KCl}, 1.2 \mathrm{KH}_{2} \mathrm{PO}_{4}, 2.4 \mathrm{CaCl}_{2}, 1.3 \mathrm{MgSO}_{4}, 26 \mathrm{NaHCO}_{3}$, and 25 D-glucose. AMPA-mediated spontaneous EPSC (sEPSC), miniature EPSC (mEPSC), and evoked EPSC (eEPSC) currents were recorded from neurons clamped at $-70 \mathrm{mV}$ in the presence of $10 \mu \mathrm{M}$ bicuculline and 5 $\mu \mathrm{M}$ strychnine. mEPSCs were identified after the addition of $0.5 \mu \mathrm{M}$ tetrodotoxin to the bath solution. The intracellular pipette solution contained the following (in $\mathrm{mM}$ ): 125 gluconic acid lactone, $15 \mathrm{CsCl}, 10$ EGTA, $10 \mathrm{HEPES}, 1 \mathrm{CaCl}_{2}, 2 \mathrm{Mg}_{2} \mathrm{ATP}$, and $0.5 \mathrm{NaGTP}$ adjusted to $\mathrm{pH}$ 7.2 with $\mathrm{CsOH}$.

HEK293 cell culture and transfection. HEK and HEK-Blue hTLR4 cells were from InvivoGen. HEK-Blue-hTLR4 cells were obtained by cotransfection of the human TLR4, MD-2, and CD14 coreceptor genes and an inducible secreted embryonic alkaline phosphatase reporter gene into HEK293 cells. HEK cells were cultured in DMEM supplemented with 4.5 $\mathrm{g} / \mathrm{L}$ glucose, $10 \%$ (v/v) fetal bovine serum, $50 \mathrm{U} / \mathrm{ml}$ penicillin, $50 \mathrm{mg} / \mathrm{ml}$ streptomycin, $100 \mathrm{mg} / \mathrm{ml}$ Normocin, and $2 \mathrm{~mm}$ L-glutamine. This medium was further supplemented with HEK-Blue selection medium (InvivoGen) to enhance stability of the HEK-Blue hTLR4 cells. The pCMV6-AC-hTRPV1-GFP plasmid was obtained from OriGene Technologies to induce expression of the human TRPV1 receptor in these cells. Transfection ( $2 \mu \mathrm{g}$ of cDNA) was performed with Lipofectamine 2000 transfection reagent (Invitrogen) as the density of the cultured cells reached $\sim 50-70 \%$ confluence. The transfected cells were cultured in the same growth medium for $24 \mathrm{~h}$ before electrophysiological recording.

Human DRG preparation. Human DRG sensory neurons were isolated from patients at M.D. Anderson Cancer Center who provided legal written informed consent for the use of their tissue in research. Each donor was undergoing spinal surgery for their disease treatment from which the dorsal root was to be harvested as standard of care. The human subjects' protocol was reviewed and approved by the M.D. Anderson Institutional Review Board.

Immediately after each ganglion was excised in the operating room, it was immersed into cold $\left(4^{\circ} \mathrm{C}\right)$, sterile balanced salt solution containing 
nutrients and transported to the laboratory in a sealed $50 \mathrm{ml}$ centrifuge tube. On arrival to the laboratory ganglia for immunohistochemical study were divided into quarters and then immersed into $4 \%$ paraformaldehyde and then processed as described above for the rat tissues. DRG for physiological recordings were dissociated according to a protocol and using medium provided by AnaBios (Davidson et al., 2014). Specifically, the sheath and budding nerve fibers from the ganglion were separated and the ganglia cut into $\sim 3 \mathrm{~mm}^{3}$ pieces and then digested for $120 \mathrm{~min}$ at $37^{\circ} \mathrm{C}$ in AnaBios digestion medium. Each ganglion was mechanically dissociated by gentle suspension and triturated until cloudy using a fire-polished sterile glass Pasteur pipette; neurons were placed on coverslips that had been precoated with poly-ornithine. Neurons were cultured at $37^{\circ} \mathrm{C}$ with $5 \% \mathrm{CO}_{2}$ in DMEM/F12 supplemented with $10 \%$ horse serum, $2 \mathrm{~mm}$ glutamine, $25 \mathrm{ng} / \mathrm{ml} \mathrm{hNGF,} 25 \mathrm{ng} / \mathrm{ml} \mathrm{hGDNF}$, and penicillin/streptomycin. Half of the culture medium was replaced with fresh medium every $3 \mathrm{~d}$ (Davidson et al., 2014). Only neurons with a stable resting membrane potential of at least $-40 \mathrm{mV}$ and evoked spikes that overshot $0 \mathrm{mV}$ were used for further recording and analysis. Series resistance was compensated to $>70 \%$. All recordings were made at room temperature.

Chemicals. All drugs and chemicals used for the dissections and recordings were of analytical grade and purchased from Sigma-Aldrich. Tetrodotoxin citrate was purchased from Tocris Bioscience. Capsaicin (Sigma-Aldrich) and SB366791 (Tocris Bioscience) were dissolved in dimethylsulfoxide (DMSO; Sigma-Aldrich), which had a concentration $<0.1 \%$ in the final solution. AMG9810 (Tocris Bioscience) and LPS-RS ultrapure (InvivoGen) were suspended in endotoxin-free PBS.

Statistics. Data were expressed as mean \pm SEM and analyzed with GraphPad Prism version 6 software. Behavioral data were analyzed with two-way ANOVA (treatment $\times$ time) followed by a Bonferroni post hoc test. The cell counts for immune-positive neurons and the percentages of neurons that colocalized with IB4 or CGRP were compared using the Mann-Whitney $U$ test. Calcium imaging data were analyzed by one-way ANOVA. Action potential frequency across 2 min segments before and after drug application were analyzed using paired $t$ test, whereas sEPSC data (also 2 min segments) were analyzed with two-way ANOVA (group $\times$ time) followed by Newman-Keuls post hoc tests. Only EPSCs with amplitudes of $5 \mathrm{pA}$ or greater (which corresponded to at least twice the recording noise level) were included in the frequency analysis. In the case of amplitude analysis, the same events and data segments were used. mEPSC frequency and amplitude after drug application were normalized to the control value and compared using by one-way ANOVA with post hoc test (Student-Newman-Keuls Method). $p<0.05$ was considered statistically significant.

\section{Results}

Paclitaxel-induced hyperalgesia is prevented and reversed by a TRPV1 antagonist

The effects of the TRPV1 antagonist AMG9810 given both during the induction of and on preestablished paclitaxel hyperalgesia was assessed in the first set of experiments. Figure $1 A$ shows the results of intrathecal administration of AMG9810 in preventing paclitaxel-induced hyperalgesia. The drug (15 $\mu \mathrm{g}$ in $20 \mu \mathrm{l}$ of PBS) or vehicle $(20 \mu \mathrm{l}$ of PBS) was given daily beginning $2 \mathrm{~d}$ before and continuing through $2 \mathrm{~d}$ after paclitaxel treatment. AMG9810 had no effect on baseline mechanical withdrawal threshold and showed no interaction with the paclitaxel vehicle (Cremophor EL) over time. The paclitaxel-vehicle-treated rats $(n=5)$ showed the expected decrease in mechanical withdrawal threshold that was significantly different from that of the vehicle-treated rats (both the vehicle-vehicle and vehicle-AMG9810 groups) by day 7 and maximal by day 14 , which is consistent with previous studies by our group (Boyette-Davis et al., 2011a; Zhang et al., 2013a; Li et al., 2014b). In contrast, the paclitaxel-AMG9810-treated rats showed only a partial development of mechanical hypersensitivity that was significantly less than that of the
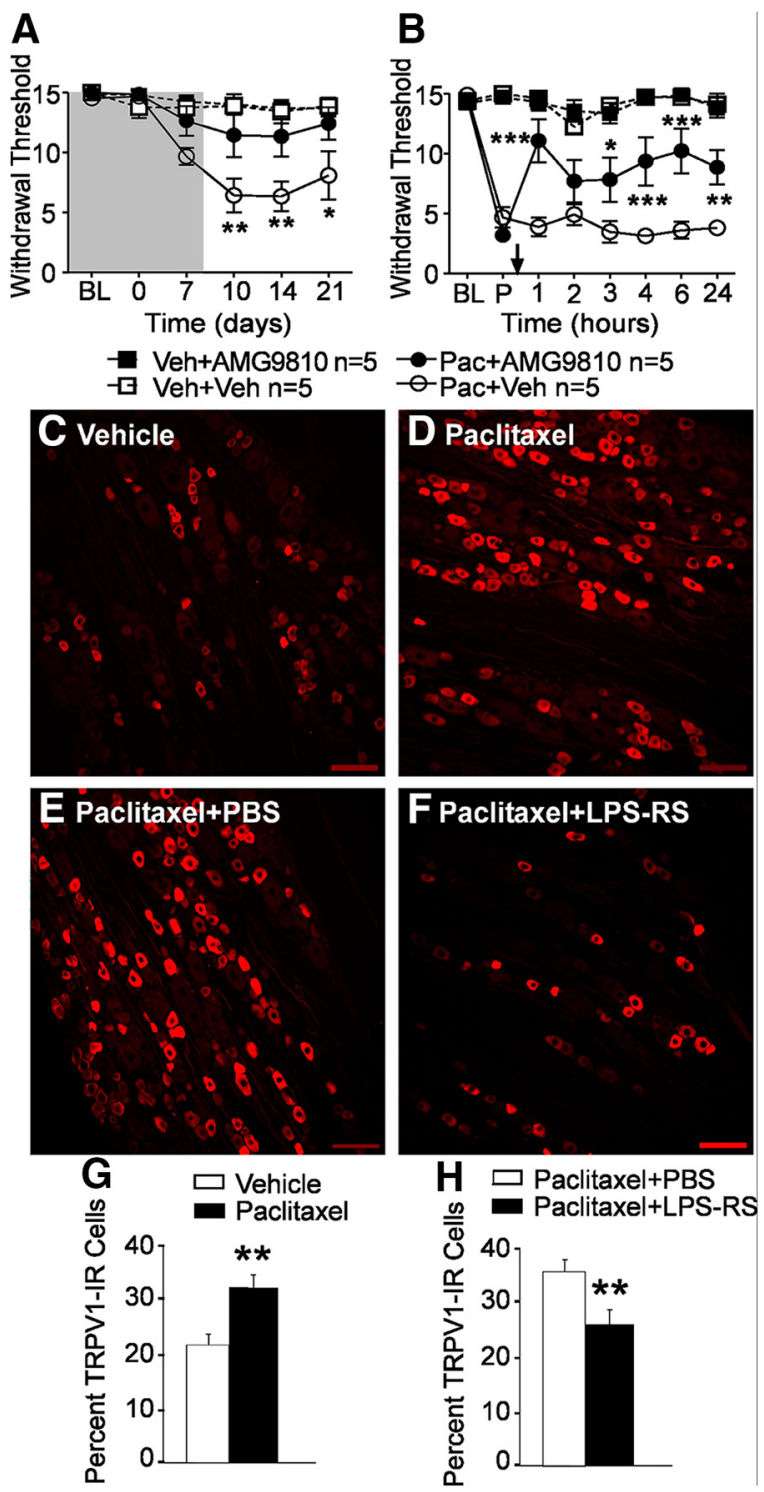

Figure 1. $\quad \boldsymbol{A}, \boldsymbol{B}$, Prevention and reversal of paclitaxel-induced hyperalgesia by intrathecal injection of a TRPV1 antagonist (AMG9810). The baseline (BL) behavioral test in $\boldsymbol{A}$ and $\boldsymbol{B}$ were collected before paclitaxel (Pac) or vehicle (Veh) treatments. In $\boldsymbol{A}$, the gray shading indicates the time of treatment with $15 \mu \mathrm{g}$ of AMG9810 (intrathecal) or vehicle solution. In $\boldsymbol{B}$, paclitaxelinduced mechanical hypersensitivity was confirmed as significant from Veh-Veh-treated rats (open squares, $n=5$ ) at $14 \mathrm{~d}$ after treatment $(\mathrm{P})$ in two groups (open and filled circles, $n=5$ each); rats were then treated with $15 \mu \mathrm{g}$ of the TRPV1 antagonist AMG9810 intrathecally (filled circles) or vehicle solution (open circles) as indicated by the arrow. ${ }^{*} p<0.05$; ${ }^{* *} p<0.01$;

${ }^{* * *} p<0.001$; two-way ANOVA followed by Bonferroni post hoc test. The representative image in C shows the baseline staining of TRPV1 (red) in the DRG in vehicle-treated rats that was not different from naive rats (data not shown); TRPV1 staining becomes elevated by day 7 after paclitaxel treatment $(\boldsymbol{D})$. Cotreatment of rats with PBS (intrathecally) with paclitaxel did not affect the increased staining of TRPV1 $(\boldsymbol{E})$, whereas cotreatment with LPS-RS (intrathecally) completely prevented the increase in TRPV1 $(\boldsymbol{F})$. As indicated by the bar graphs in $\mathbf{G}$, the increase in TRPV $1{ }^{+}$neurons by paclitaxel was statistically significant $\left({ }^{* *} p<0.01\right)$, whereas in $\boldsymbol{H}$, this was significantly less in the LPS-RS-treated rats versus the PBS-treated rats. Scale bar, $100 \mu \mathrm{m} .{ }^{* *} p<0.01$.

paclitaxel-vehicle-treated rats at days 7-21. The paclitaxelAMG9810-treated rats showed no significant difference from the vehicle-treated rats in withdrawal threshold.

In the second experiment, AMG9810 was tested as a treatment for preestablished paclitaxel-induced hyperalgesia (Fig. $1 B)$. Two groups were treated with paclitaxel and mechanical 

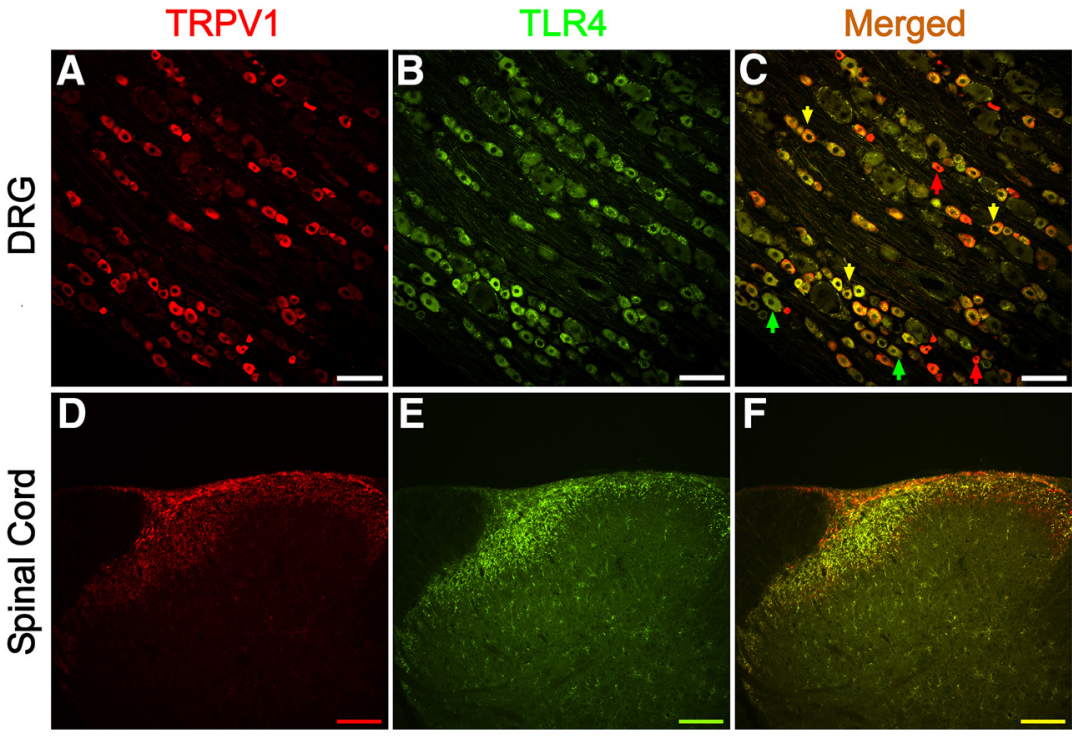

G Paclitaxel $12.5 \mu \mathrm{M}$
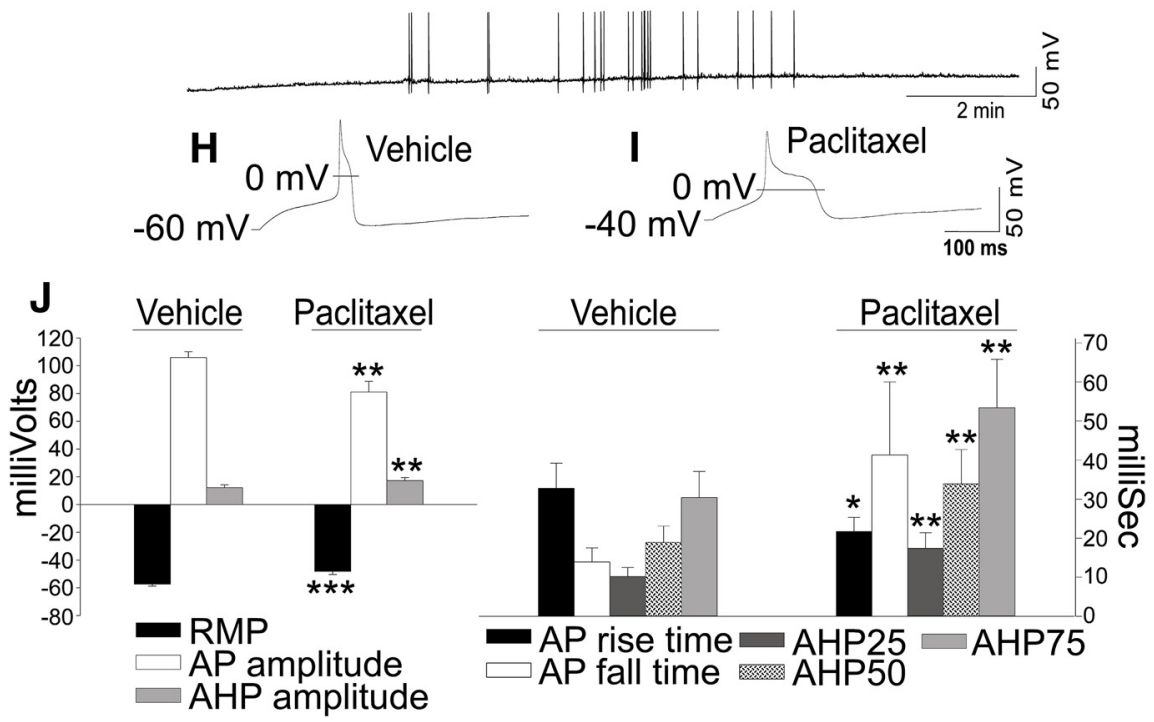

Figure 2. TRPV1 is colocalized with TLR4 in DRG neurons and afferent terminals in the spinal cord. TRPV1 alone is shown in red in the left column for DRG neurons in $\boldsymbol{A}$ and in spinal terminals in $\boldsymbol{D}$. TLR4 staining in subsets of DRG neurons is shown in green in $\boldsymbol{B}$ and spinal terminals in $\boldsymbol{E}$ (center column). Colocalization of the two are shown in the merged image by yellow for DRG in the right column $(\boldsymbol{C})$, as well as in fiber profiles in the superficial spinal dorsal horn $(\boldsymbol{F})$. Scale bar, $100 \mu \mathrm{m}$. The representative recording in $\boldsymbol{G}$ shows that acute application of paclitaxel $(12.5 \mu \mathrm{m})$ evoked spontaneous action potentials in subsets of DRG neurons from animals treated with paclitaxel. In $\boldsymbol{H}$ and $\boldsymbol{I}$, representative action potential waveforms for the neuron in $\mathbf{G}$ evoked by direct current injection after 5 min of vehicle treatment and then after $5 \mathrm{~min}$ of acute perfusion with $12.5 \mu \mathrm{m}$ paclitaxel are shown. The bar graphs in $\boldsymbol{J}$ show the group data for the effects of paclitaxel on several action potential properties. AP, Action potential; RMP, resting membrane potential; AHP, after-hyperpolarization; AHPxx\%, interval to each percentage of maximal amplitude. ${ }^{*} p<0.05$; ${ }^{* *} p<0.01 ;{ }^{* * *} p<0.001$ paclitaxel versus vehicle; paired $t$ test.

hyperalgesia was confirmed in each group at day 14 after treatment. Rats in both groups were given a single intrathecal dose of either $15 \mu \mathrm{g}$ of AMG9810 in $20 \mu \mathrm{l}$ of PBS $(n=5)$ or just 20 $\mu l$ of PBS $(n=5)$. The AMG9810 group showed a significant increase in mechanical withdrawal threshold that was evident within the first hour after treatment compared with the vehicle group and this effect persisted through $24 \mathrm{~h}$ after treatment. None of the animals that received any intrathecal injections showed any change in motor performance as assessed using the rotarod test (data not shown).
TRPV1 is expressed in more DRG neurons in rats with paclitaxel hyperalgesia

The basis for the role of TRPV1 in paclitaxel hyperalgesia was explored in a series of follow-up experiments, the first of which was to confirm whether paclitaxel increases expression of TRPV1 in sensory neurons. The L4-L5 DRG and spinal cord were collected from rats with confirmed paclitaxel hyperalgesia and the numbers of TRPV ${ }^{+}$cells determined by immunohistochemistry (IHC) at day 7 after paclitaxel treatment. As shown in Figure 1, $\mathrm{C}-\mathrm{H}$, the number of neurons in the DRG that were positive for TRPV1 increased after paclitaxel treatment compared with rats that received vehicle (cf. Fig. $1 C, D$ ). Overall, the mean number of TRPV1 ${ }^{+}$ cells in the DRG increased from $21.12 \pm$ $1.9 \%$ to $31.6 \pm 2.07 \%$ of all cells counted $(p<0.01$; Fig. $1 G)$. Importantly, the paclitaxel-induced increase in TRPV1 ${ }^{+}$ neurons was prevented by coadministration of LPS-RS (from $35.78 \pm 2.08 \%$ to $25.87 \pm 2.77 \%, p<0.01$; Fig. $1 H$ ).

The pattern of TRPV1 localization in the DRG is very similar to that for TLR4 (Li et al., 2014b), so possible colocalization of TRPV1 with TLR4 was tested. As shown in Figure 2, IHC double staining revealed that TRPV1 is indeed colocalized with TLR4 in small DRG neurons (Fig. $2 C$, yellow arrows), although there were also populations of neurons that expressed TRPV1 (red arrow) or TLR4 (green arrow) alone. As shown in Figure 2, $D-F$, colocalization of TRPV1 and TLR4 was also observed in the spinal cord, but only in the most superficial layers, where peripheral fibers enter. The remainder of TLR4 observed in the dorsal horn was in profiles consistent with astrocytes described previously (Li et al., 2014b). There was no TRPV1 localized in spinal neurons or glial cells (Fig. $2 F$ ).

\section{LPS and paclitaxel enhance excitability} of DRG neurons in CIPN rats

The functionality of TLR4 receptors in DRG neurons was tested using whole-cell recordings in vitro and direct application of LPS and paclitaxel. In naive rats, acute application of neither LPS nor paclitaxel induced increases in spontaneous action potentials. LPS did induce an increase of neuronal excitability after incubation for $24 \mathrm{~h}$ resulting in reduced rheobase and an increased numbers of action potential discharges to suprathreshold current injection (Ochoa-Cortes et al., 2010). Because TLR4 was upregulated in rat DRG at day 7 after paclitaxel treatment, DRG neurons were retested for LPS and paclitaxel responsiveness at this time. LPS $(1 \mu \mathrm{g} / \mathrm{ml})$ and paclitaxel $(12.5 \mu \mathrm{M})$ both now evoked action potentials. The concentration of paclitaxel in these experiments was intended to ap- 

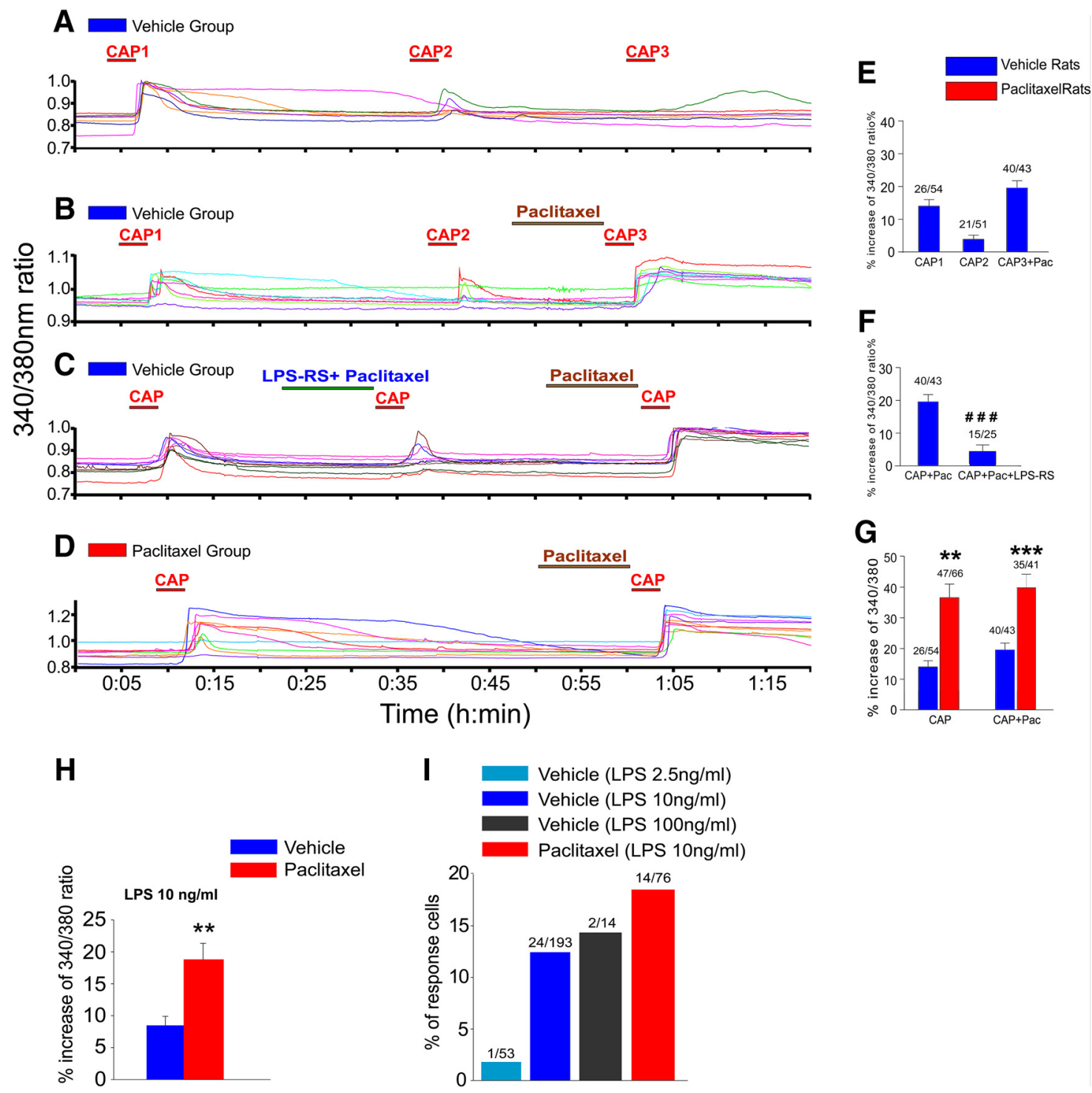

Figure 3. TRPV1 sensitization by paclitaxel and LPS in DRG neurons shown using calcium imaging. Representative calcium imaging results of change in $340 / 380$ ratio in dissociated DRG neurons after perfusions of capsaicin (CAP, $200 \mathrm{~nm}$ ) alone and in combination with paclitaxel $(12.5 \mu \mathrm{M})$ or paclitaxel plus LPS-RS $(2 \mu \mathrm{g} / \mathrm{ml})$ are shown in $\boldsymbol{A}-\boldsymbol{D}$, each colored line is a single neuron and the time of each application is indicated by the bars over the traces. The bar graphs show the grouped results for experiments testing the interactions between paclitaxel on the responses to capsaicin ( $\boldsymbol{E}-\boldsymbol{G})$ on the effects of LPS on DRG neurons alone $(\boldsymbol{H})$ and the effects of LPS on DRG neurons from vehicle- and paclitaxel-treated rats $(\boldsymbol{I}) .{ }^{* *} p<0.01 ;{ }^{* * *} p<0.001$, vehicle rats versus paclitaxel rats; $\# \#$ \# $<0.001$, CAP + Pac versus CAP + Pac + LPS-RS.

proximate the peak level that would occur in the DRG after a cumulative dose of $8.0 \mathrm{mg} / \mathrm{kg}$ paclitaxel, as in the behavioral studies, based on what was observed in the rat DRG $1 \mathrm{~d}$ after this dosing scheme (Xiao et al., 2011) and assuming 4.5 half-time clearances of paclitaxel (Lian et al., 2013). An example of a DRG neuron from a paclitaxel-treated rat is shown in Figure $2 G$ (LPS results not shown). Like LPS, paclitaxel-treated neurons showed bursts of action potentials during acute application (Fig. 2G).

Representative single action potentials from the neuron shown in Figure $2 G$ are shown in Figure 2, $H$ and $I$, and the summarized data are shown in Figure 2J. The acute administration of paclitaxel significantly depolarized the resting membrane potential and significantly decreased rheobase (from $137 \pm 16.2$ to $101 \pm 12.5 \mathrm{pA}$, data not shown). Action potential amplitude was significantly decreased, as was action potential rising time. A significant increase in action potential falling time due to a prolongation of the sustained component of the action potential was observed, as was an increase in after-hyperpolarization ampli- tude. In addition, the time for $25 \%, 50 \%$, and $75 \%$ recovery in after-hyperpolarization were all significantly slowed.

\section{Paclitaxel treatment sensitizes the responses of DRG neurons to TRPV1}

Calcium imaging in dissociated DRG neurons from vehicletreated and paclitaxel-treated rats was used to assess whether a functional TLR4-TRPV1 interaction occurs in DRG neurons. An initial perfusion of capsaicin (200 nM) alone on DRG neurons from vehicle-treated rats resulted in a robust increase in intracellular calcium evidenced by an increase in the 340/380 ratio (Fig. $3 A$, CAP1). This response showed acute desensitization when capsaicin was reapplied $25 \mathrm{~min}$ after the first response (Fig. $3 \mathrm{~A}$, CAP2). A third perfusion of capsaicin alone showed a loss of response indicating desensitization of the receptor (Fig. $3 A$, CAP3). In contrast, as shown in Figure $3 B$, coapplication of paclitaxel $(12.5 \mu \mathrm{M})$ with capsaicin on the third test resulted in a response comparable to or greater than the initial response even 

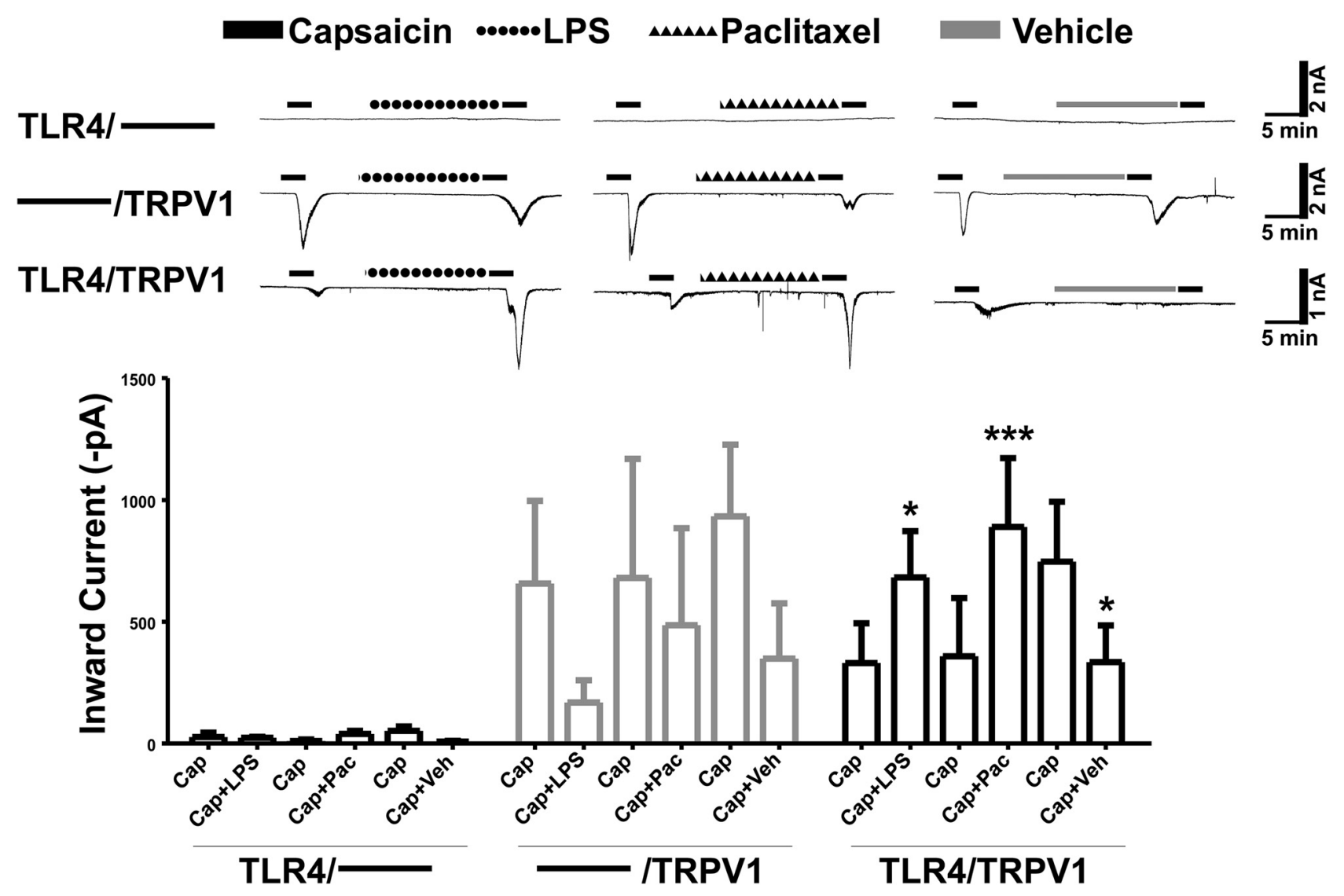

Figure 4. Interactions between TLR4 and TRPV1 in HEK 293 cells studied using whole-cell patch clamp. Inward currents were recorded in HEK293 cells transfected with TLR4 only (top line), TRPV1 only (second line), and both TLR4 and TRPV1 (line 3). The bar graphs at the bottom show the summarized responses with statistical differences determined by paired $t$ tests. Capsaicin (200 nm) did not induce inward currents in cells expressing TLR4 alone, whereas the responses to repeated capsaicin showed desensitization in cells expressing TRPV1 alone. LPS (10 ng/ml) and paclitaxel (12.5 $\mu \mathrm{M}$ ) sensitized the responses to capsaicin in cells expressing both TLR4 and TRPV1. ${ }^{*} p<0.05$, LPS + capsaicin; ${ }^{* * *} p<0.001$, paclitaxel + capsaicin; ${ }^{*} p<0.05$ vehicle solution + capsaicin versus first capsaicin response.

though the cells had shown the initial partial desensitization upon the second application of capsaicin. Finally, as shown in Figure $3 C$ (center), this acute sensitization of capsaicin response by paclitaxel was completely blocked when the TLR4 inhibitor LPS-RS $(2 \mu \mathrm{g} / \mathrm{ml})$ was applied during the paclitaxel application (Fig. $3 F$ ).

A different pattern of calcium mobilization was observed in DRG neurons from paclitaxel-treated rats. As in naive rats, DRG neurons from paclitaxel-CIPN-treated rats showed a robust intracellular calcium response to an initial capsaicin application (Fig. 3D, CAP). However, in contrast to DRG neurons from naive rats, reapplication of capsaicin onto DRG neurons from paclitaxel-treated rats produced a second (data not shown) response comparable to the initial response without evidence of desensitization. Coapplication of paclitaxel with capsaicin produced an increase in response to capsaicin in DRG neurons from both CIPN-treated rats (Fig. 3D) and vehicle-treated rats (Fig. $3 B, C, \mathrm{CAP}+\mathrm{Pac}$; summarized in Fig. $3 G$, bar graphs).

DRG neurons from naive and paclitaxel-treated rats were also tested for calcium mobilization responses to LPS alone. Figure $3 \mathrm{H}$ shows that the mean increase in $340 / 380$ ratio for DRG neurons from paclitaxel-treated rats to $10 \mathrm{ng} / \mathrm{ml}$ LPS was significantly greater that in DRG neurons from vehicle-treated rats. Figure $3 I$ shows the percentage of responsive neurons with increasing doses of LPS. DRG neurons from paclitaxel-treated rats were observed to show heightened responses to LPS in that 14 of $76(18.42 \%)$ neurons responded to $10 \mathrm{ng} / \mathrm{ml} \mathrm{LPS}$, whereas only
24 of $193(12.44 \%)$ neurons showed a response in DRG from vehicle-treated rats.

LPS or paclitaxel sensitizes TRPV1 inward currents in TLR4/ TRPV1-coexpressing HEK293 cells

Whole-cell recordings in HEK 293 cells that stably expressed human TLR4 and in which human TRPV1 was cotransfected were used to better define the functional interactions between TLR4 and TRPV1. Successfully transfected cells were confirmed by visualization of enhanced green fluorescence protein reporter. The first two lines of representative recordings in Figure 4 show responses in the matching control HEK cell lines. The recordings at the top show that the application of capsaicin (200 nM) in HEK293 cells expressing only TLR4 failed to produce any response. In these cells, the application of either LPS $(10 \mathrm{ng} / \mathrm{ml})$ or paclitaxel $(12.5 \mu \mathrm{M})$ also failed to evoke any current. Conversely, HEK cells only expressing TRPV1 exhibited robust capsaicininduced currents (Fig. 4, line 2). Reapplication of capsaicin with LPS (Fig. 4, left), paclitaxel (Fig. 4, center), or vehicle (Fig. 4, right) onto the HEK cells lacking TLR4 resulted in a desensitized response. Finally, in HEK293 cells expressing both TLR4 and TRPV1, the first application of capsaicin again produced an inward current. Due to lower transfection with both receptors (TLR4/TRPV1) than single receptor transfection (TRPV1), the first TRPV1 current in these cells as shown in the bottom trace appeared smaller than in HEK cells expressing TRPV1 alone. Application of LPS (Fig. 4, left) or paclitaxel (Fig. 4, center) pro- 
BASELINE

A Vehicle Rats

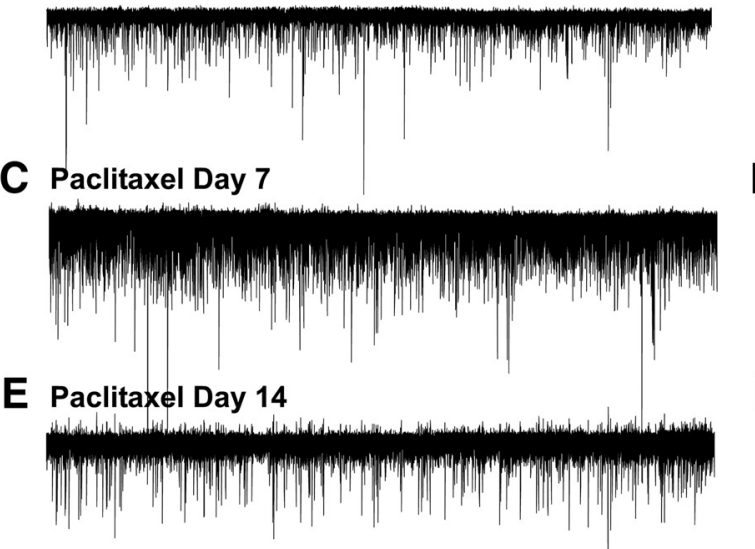

G

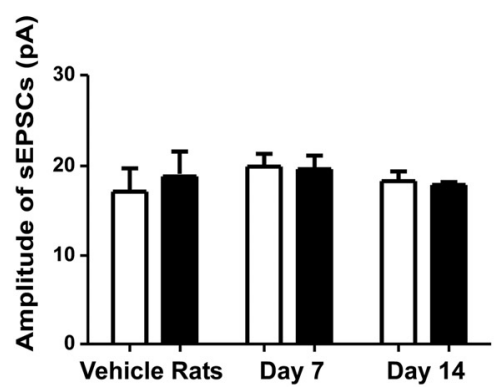

AMG 9810
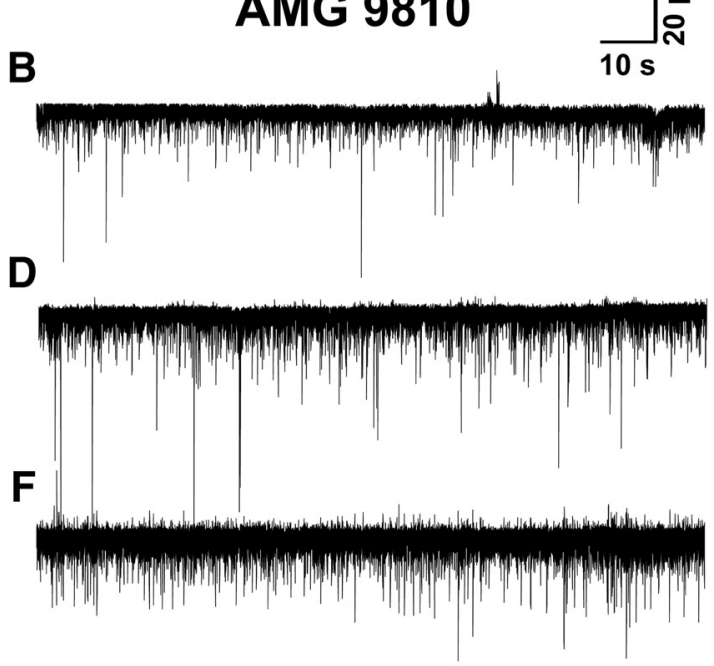

H

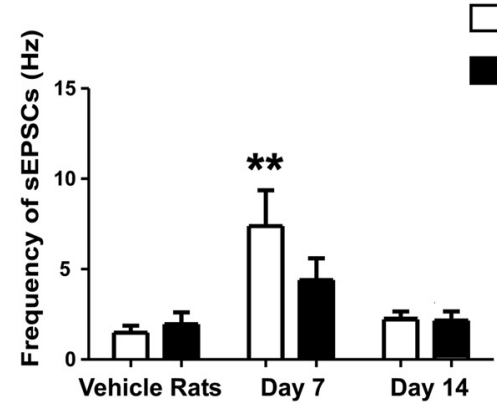

Baseline

AMG9810

Figure 5. Representative examples of whole-cell recordings for substantia gelatinosa (SG) neurons before (left) and after (right) administration of the TRPV1 antagonist AMG9810 (5 $\mu \mathrm{M}$ ) in the vehicle-treated group $(\boldsymbol{A}, \boldsymbol{B})$, day 7 paclitaxel-treated group $(\boldsymbol{C}, \boldsymbol{D})$, and day 14 paclitaxel-treated group $(\boldsymbol{E}, \boldsymbol{F})$ show increased sEPSCS only in the day 7 paclitaxel-treated group that is suppressed by the AMG9810. The washout segment is not shown. Bar graphs in $\boldsymbol{G}$ and $\boldsymbol{H}$ summarize the mean ( \pm SEM) change in amplitude $(\boldsymbol{G})$ and frequency $(\boldsymbol{H})$ of sEPSC before and after 5 min of AMG9810 application. ${ }^{* *} p<0.01$, day 7 paclitaxel-treated group versus vehicle and day 14 paclitaxel-treated groups; two-way ANOVA followed by Newman-Keuls post hoc test.

duced small inward currents in the double-transfected cells and most importantly, a second application of capsaicin after the TLR4 agonists resulted in augmented responses compared with the initial response. Application of vehicle between the first and second application of capsaicin in the TLR4/TRPV1 HEK293 cells resulted in a desensitized response. The grouped data are summarized in the bar graphs at the bottom of the figure.

Excitatory synaptic input to spinal cord SG neurons mediated by TRPV 1 is increased $7 \mathrm{~d}$ after paclitaxel treatment The possibility of an interaction between TLR 4 and TRPV1 was next tested at the spinal dorsal horn. The frequency and amplitude of sEPSCs of neurons within the substantia gelatinosa were measured in vehicle- and paclitaxel-treated rats. Figure 5 shows representative recordings from vehicle-treated rats (Fig 5A,B) and from rats at day 7 (Fig 5C,D) and 14 after paclitaxel treatment (Fig $5 E, F)$. The grouped data are shown in the bar graphs at the bottom of the figure (Fig $5 G, H$ ). The baseline recordings in the left column show that SG neurons in rats at day 7 after paclitaxel treatment (Fig. 5C) exhibited more sEPSCs than neurons from vehicle-treated rats (Fig. 5A) or from rats at day 14 after paclitaxel $\left(F_{(2,34)}=9.345, p<0.001\right.$; Fig. $\left.5 E\right)$. The mean frequency of sEPSCs in the vehicle-treated rat group was $1.48 \pm 0.31 \mathrm{~Hz}$ $(n=6)$, whereas that in the paclitaxel day 7 group was $7.38 \pm 1.8$ $\mathrm{Hz}(n=8)$. The frequency of sEPSCs returned to a level not different from baseline by day 14 after paclitaxel. As shown in the bar graphs (Fig. $5 G$, bottom left), there were no differences in amplitude of sEPSCs between groups. For example, the mean amplitude of sEPSCs in the day 7 vehicle-treated group was $17.28 \pm 2.23 \mathrm{pA}(n=6)$, whereas the mean amplitude of sEPSC in the day 7 paclitaxel-treated group was $20.17 \pm 1.07 \mathrm{pA}(n=8)$. Notably, the TRPV1 antagonist AMG9810 suppressed the increased sEPSC frequency in the day 7 paclitaxel rats such that the sEPSC frequency after AMG9810 in the day 7 paclitaxel-treated group was not different from baseline sEPSC frequency in naive rats $\left(F_{(1,34)}=0.871, p=0.3573\right)$. This is seen in the representative recordings in Figure 5, $C$ and $D$, comparing the left column with the recording in the right column as well as in the grouped results in the bar graphs at bottom right. AMG9810 had no effects on sEPSC frequency in either the vehicle or the day 14 paclitaxeltreated rats.

Direct effects of paclitaxel on mEPSCs in rat spinal neurons Very low levels (50 $\mathrm{nm}$ ) of paclitaxel are detectable in the spinal cord at day 7, but are not detectable by day 16 using the treatment protocol as described in this study (Xiao et al., 2011). As shown in Figure $6 A$, acute paclitaxel application $(50 \mathrm{~nm})$ onto superficial dorsal horn neurons in rat spinal cord slices increased mEPSC frequency compared with vehicle control (Fig. 6A). This effect was blocked when paclitaxel was coapplied with the TRPV1 antagonist SB366791 (10 $\mu \mathrm{M}$; Fig. 6B), whereas the antagonist alone did not change mEPSC frequency (Fig. $6 B$, center). These effects were highly significant across the groups of neurons tested (Fig. 6C). Paclitaxel application did not change the frequency (Fig. 6D) 
A
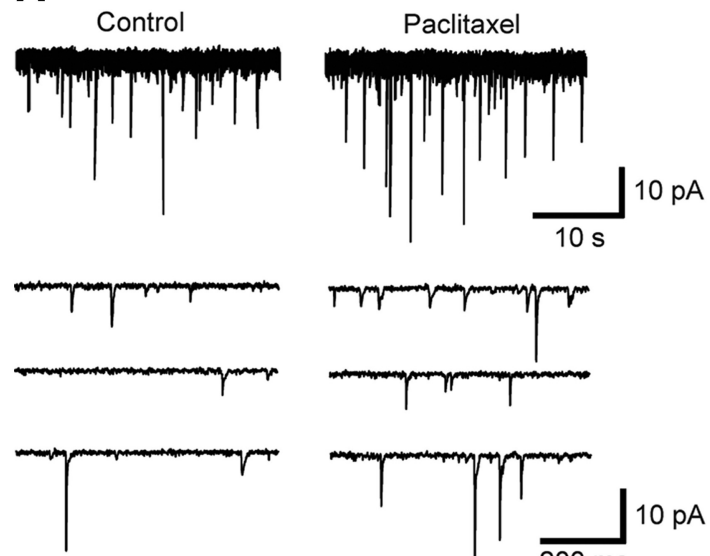

C
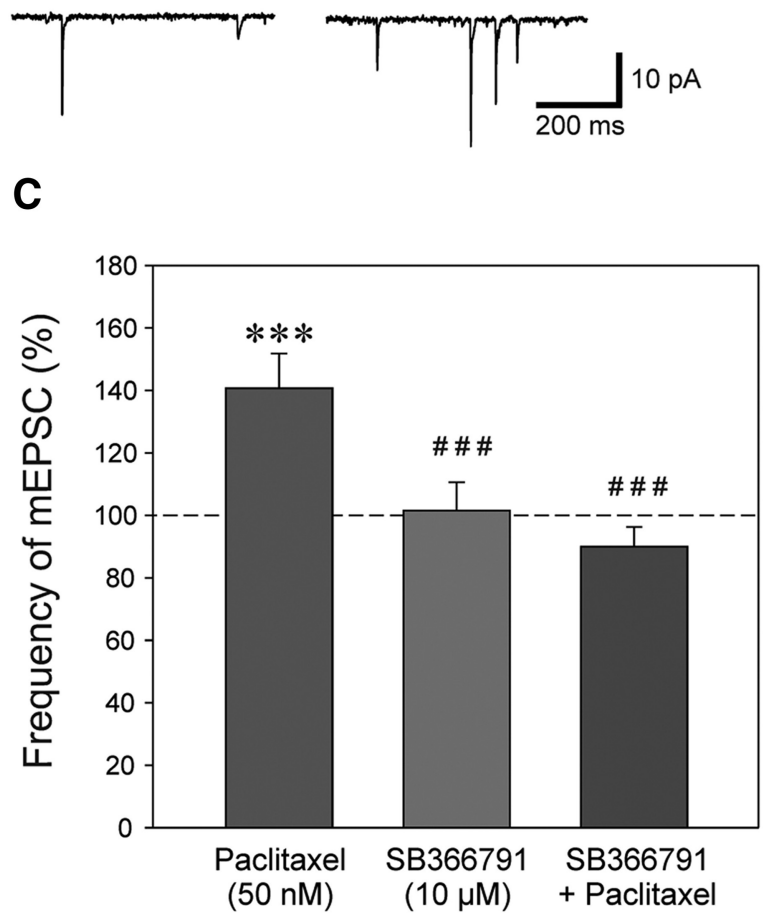

B
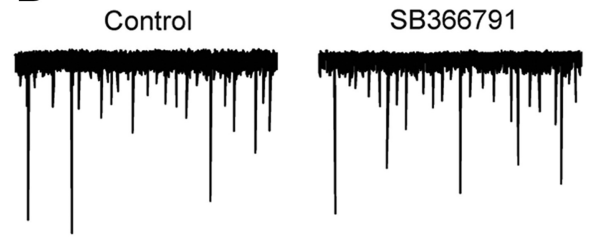

SB366791 + Paclitaxel
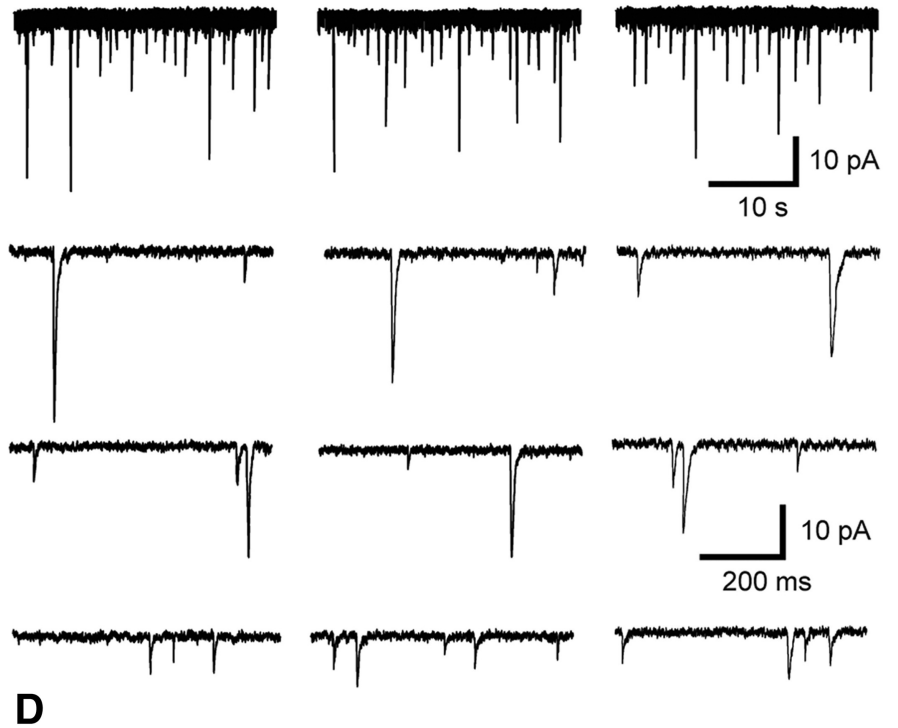

D

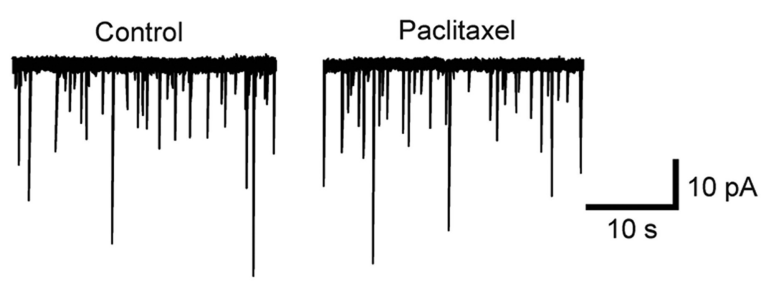

E
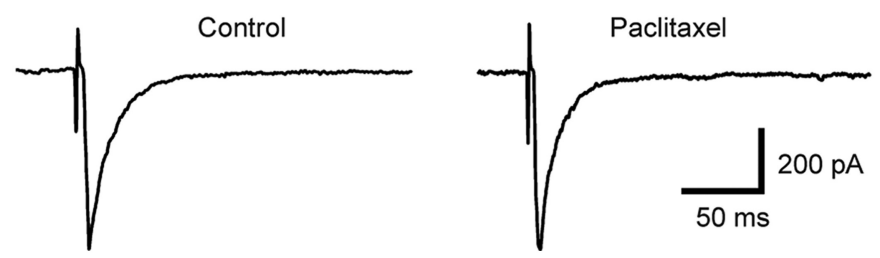

Figure 6. Paclitaxel application increased mEPSC frequency in superficial dorsal horn neurons in rat spinal cord slice. $\boldsymbol{A}$, Native recording of mEPSC activity before and after paclitaxel $(50 \mathrm{~nm})$ application. $\boldsymbol{B}$, The TRPV1 antagonist SB366791 (10 $\mu \mathrm{M})$ did not change the mEPSC frequency but prevented its increase during coapplication with paclitaxel. $\boldsymbol{C}$, Averaged responses demonstrate that paclitaxel treatment induced a significant increase in $\mathrm{mEPSC}$ frequency compared with the baseline (control, $100 \%)$ value (140.7 $\pm 11.1 \% ; n=14$ ). This increase was prevented by the TRPV1 antagonist (SB366791+ paclitaxel) treatment, whereas the antagonist alone had no effect (SB366791; $n=10)$. D, Paclitaxel (50 nM) application did not change the frequency or amplitude of the sEPSCS or the amplitude of the dorsal root sEPSCS $(\boldsymbol{E})$. ${ }^{* * *} p<0.001$ versus control values; \#\#\# $<0.001$ versus paclitaxel; one-way ANOVA followed by Student-Newman-Keuls test.

or the amplitude of sEPSCs (Fig. 6D) or the amplitude of EPSCs evoked by dorsal root stimulation (Fig. $6 E$ ).

\section{Acute paclitaxel application enhances spinal TRPV1 responses via TLR4}

The possibility that paclitaxel increases mEPSC frequency by an effect mediated by TLR4 was tested in mouse spinal dorsal horn. As shown in the top line of the representative recordings (Fig. $7 A$ ), an initial application of capsaicin (200 nM) evoked an increase in mEPSCs $(9.9 \pm 1.7 \mathrm{~Hz})$ and the second response to capsaicin was notably reduced compared with the first (Fig. $7 A, D)$. Figure $7 B$ (middle trace) shows that paclitaxel (50 nM), when applied alone after an initial application of capsaicin, evokes an increase in mEPSCs, but also prevents the decrease in response to a second capsaicin application. Coapplication of LPS-RS with paclitaxel (Fig. $7 C$ ) prevented both the acute increase in mEPSC frequency induced by paclitaxel and the salvage of the second capsaicin response. In Fig. $7 D$, the mean normalized responses are shown for each group, where the responses to the second capsaicin application are expressed as percentage of the first application. The second response to capsaicin averaged $32.6 \pm 6.0 \%$ of the first in the control group (CTRL, $n=8$ ). In contrast, the second response to capsaicin applied after paclitaxel was $90.8 \pm 12.3 \%$ of the first response (paclitaxel, $n=10$ ). Finally, the second response to capsaicin averaged $44.2 \pm 7.3 \%$ of the first in the LPS-RS + Paclitaxel group (right bar, $n=12$ ). The increase in mEPSC frequency 5 min after the first capsaicin application was pronounced in the presence of paclitaxel (Fig. 7E). The mEPSC frequency at the 5-6 min interval in the paclitaxel group (34.0 $\pm 6.1 \%$ of the capsaicin response, $n=10$ ) was significantly higher compared with the frequency in the control $(13.1 \pm 4.6 \% ; n=8)$ and the LPS-RS $(17.7 \pm 4.4 \% ; n=12)$ groups.

Translation of findings from rodent to human DRG

As a first step in translating the findings and to further confirm the hypothesis that paclitaxel activates TLR4 and sensitizes TRPV1 contributing to CIPN, we first assessed whether TLR4 
A

Control group

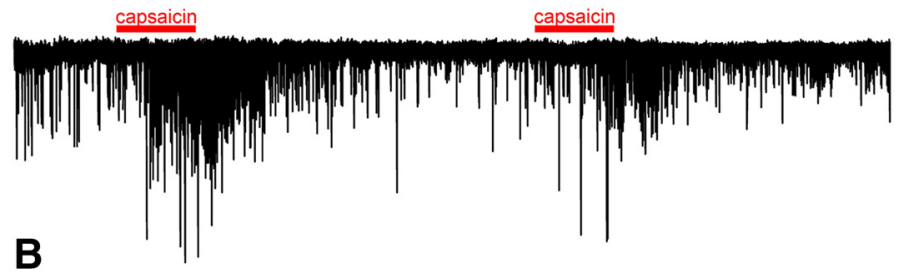

Paclitaxel group

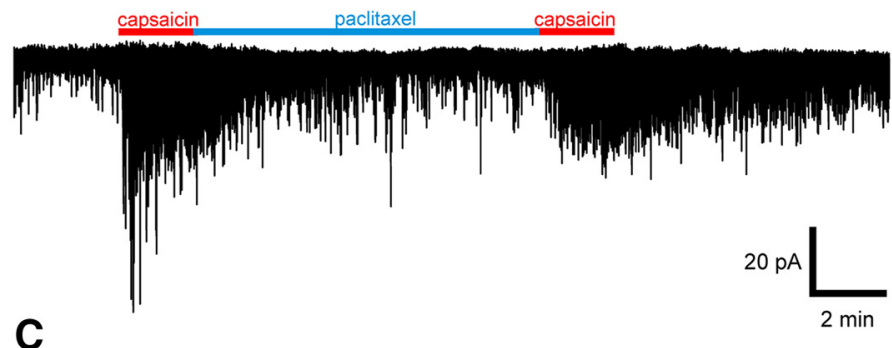

C

TLR4 antagonist + Paclitaxel group

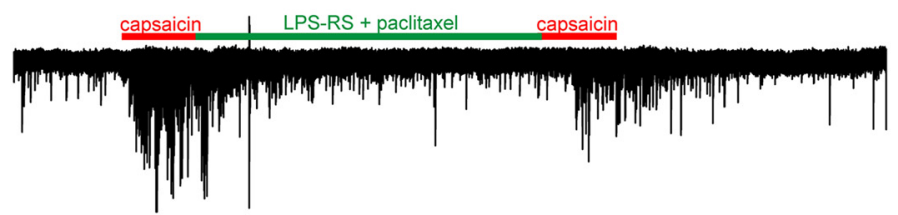

D

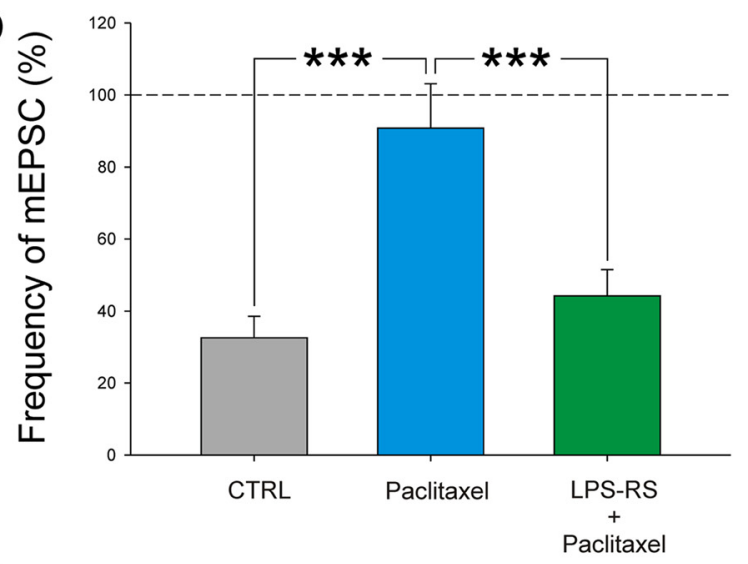

E

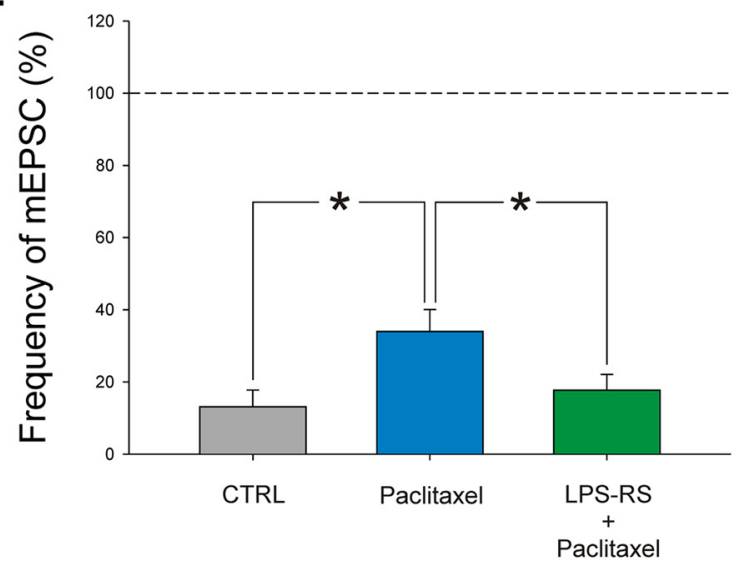

Figure 7. Representative traces showing that capsaicin (200 nm) increases mEPSCs in spinal neurons and that the second response was notably reduced compared with the first one in vehicle-treated mice $(\boldsymbol{A})$. Acute application of paclitaxel $(50 \mathrm{~nm})$ for $10 \mathrm{~min}$ before the second capsaicin application prevented the decrease of the second response $(\boldsymbol{B})$. Coapplication of paclitaxel with the TLR4 antagonist LPS-RS $(2 \mu \mathrm{g} / \mathrm{ml})$ prevented the effect of paclitaxel and on the second capsaicin response, with the result being desensitization, as seen in the control group ( $\boldsymbol{C}$ ). In $\boldsymbol{D}$, the mean normalized responses are shown for each group $(n=8)$ where the responses to the second capsaicin application are expressed as a percentage of the first application. The mean increase in mEPSC frequency 5 min after the first capsaicin application was pronounced in the presence of paclitaxel $(\boldsymbol{E})$. ${ }^{* * *} p<0.001$; ${ }^{*} p<0.05$ versus paclitaxel-treated group; one-way ANOVA followed by Student-Newman-Keuls test.

and TRPV1 are colocalized in human DRG neurons. As shown in Figure 8, IHC confirms that human DRG do in fact coexpress both receptors. TRPV $1^{+}$neurons are shown in Figure $8 A$ in red. Figure $8 B$ shows TLR $4^{+}$human DRG neurons in green. Finally, Figure $8 C$ shows the merged images of neurons positive for both TRPV1 and TLR4 in yellow with several specific double-positive neurons indicated by yellow arrows. Cells positive for TRPV1 alone and TLR4 alone are indicated by red and green arrows, respectively.

Figure $8, D-F$, shows results from whole-cell patch clamp recordings in human DRG neurons that validate the functional nature of these receptors. Approximately one-third of the neurons ( six of 15) failed to respond to either capsaicin or paclitaxel (data not shown). The trace in Figure $8 D$ shows a neuron that responded to capsaicin, but failed to show any response to paclitaxel. This cell exhibited desensitization to a second capsaicin application when tested $30 \mathrm{~min}$ after the initial application (Fig. 8 , right center trace, $6 / 15$ neurons). The trace in Figure $8 E$ shows a third representative neuron (3/15 neurons) that responded to an initial administration of capsaicin. The center panel shows that this same neuron responded with a small burst of action potentials when paclitaxel was applied. Finally, the cell showed an augmented response to a second capsaicin application when tested $30 \mathrm{~min}$ after the first capsaicin application (Fig. $8 E$, right). The bar graphs at the bottom show the summarized response for the type 2 and 3 neurons. The baseline response to capsaicin was not different between groups. The second response to capsaicin was significantly reduced compared with the first in the type 2 neurons. The type 3 neurons showed significantly greater responses to paclitaxel than did type 2 neurons; and type 3 neurons showed a significantly increased response to the second application of capsaicin compared with the first.

\section{Discussion}

This study demonstrates that paclitaxel and LPS can activate peripheral sensory and spinal neurons directly and sensitize these cells to TRPV1-mediated capsaicin responses via TLR4. Although this study was not the first to demonstrate that LPS has direct effects on neuronal activation and sensitization of sensory neurons to TRPV1 (Diogenes et al., 2011), it is the first in which a direct functional interaction between TLR4 and TRPV1 has been shown in rats and human DRG neurons, TLR4/TRPV1-coexpressing HEK293 cells, and in both rat and mouse spinal cord slices. Moreover and more specifically, this is the first study in which this interaction has been shown to play an important role in the generation of behavioral hypersensitivity in paclitaxel-related CIPN. The key translational implications are that TLR4 and TRPV1 antagonists may be useful in the prevention and treatment of CIPN in humans. 

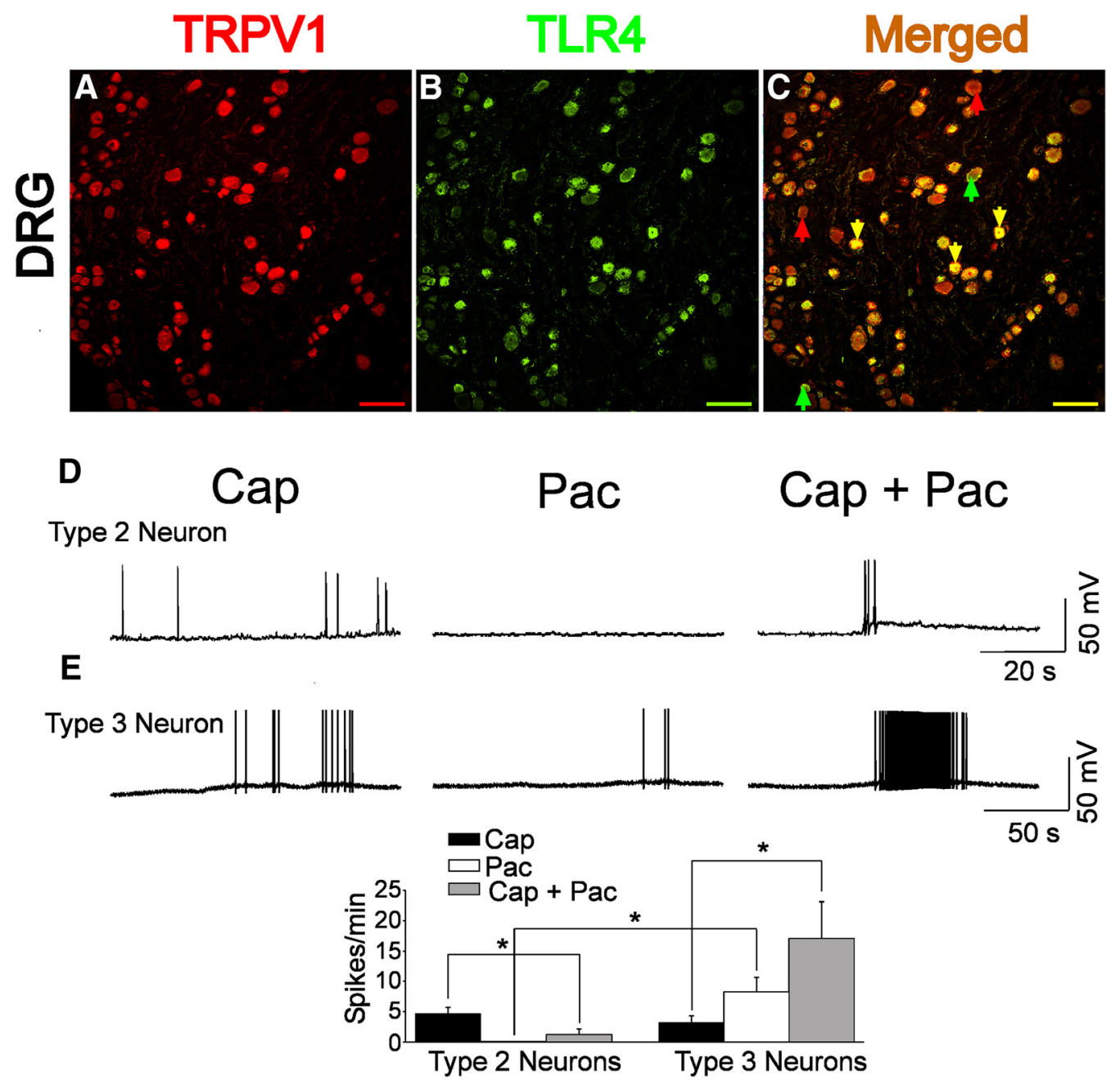

Figure 8. Immunofluorescent double staining shows that TRPV1 $($ red, $\boldsymbol{A}$ ) is colocalized with TLR4 (green, $\boldsymbol{B}$ ) in human DRG neurons (yellow in merged image at right, $\boldsymbol{C}$ ). The red arrows in the merged image indicate cells only showing TRPV1, the green arrows indicate cells only expressing TLR4, and the yellows arrow points to cells positive for both TRPV1 and TLR4. Scale bar, $200 \mu \mathrm{m}$. Three types of responses were observed when human DRG neurons were tested by application of capsaicin (Cap) and paclitaxel (Pac). Type 1 neurons did not respond to either capsaicin or paclitaxel (data not shown). Type 2 neurons (D) responded positively to capsaicin (left column), showed no responses to paclitaxel (center column), and then showed desensitization to a second application of capsaicin (right column). Type 3 neurons $(\boldsymbol{E}$ ) showed responses to capsaicin (left column) and to paclitaxel (center column) and then showed a facilitation of response to the repeated application of capsaicin (right column). The bar graphs at the bottom show the summarized response for the type 2 and 3 neurons. The baseline response to capsaicin was not different between groups. The second response to capsaicin was significantly reduced compared with the first in the type 2 neurons. The type 3 neurons showed significantly greater responses to paclitaxel than did type 2 neurons; and type 3 neurons showed a significantly increased response to the second application of capsaicin compared with the first. ${ }^{*} p<0.05$; Mann-Whitney U test.

It is striking that the pattern of increased excitability in spinal and sensory neurons by paclitaxel is very similar to that induced by LPS. Because a TLR4 antagonist prevented both LPS and paclitaxel effects on sensory neurons, this clearly suggests a role of TLR4 in mediating the effects of both on sensory neurons and thus in generating paclitaxel CIPN. Although our data confirm the findings of others in rats (Hara et al., 2013), a third study only found a weak effect of TRPV1 inhibition on mechanical hypersensitivity in mice treated with paclitaxel (Sałat and Filipek, 2015); this was most likely due to the fact that AMG9810 is a more potent TRPV1 antagonist (Gavva et al., 2005) than used in the study on mice.

The key questions now center on the specific mechanisms that are engaged. The findings here that a TRPV1 antagonist also reduces signs of the paclitaxel CIPN behavioral hypersensitivity suggests that paclitaxel activates TLR4 and signals downstream to this to sensitize TRPV1. Increased TRPV1 signaling in cutaneous afferents may then correspond to the sensation of burning in the skin (Simone et al., 1989), whereas increased signaling of TRPV1 in deep somatic tissue afferents may underlie the deep aching and cramping (Marchettini et al., 1996; Witting et al., 2000) reported by CIPN patients (Boyette-Davis et al., 2011b; Boyette-Davis et al., 2013). The changes in action potential parameters induced by paclitaxel indicate an increased excitability of rat DRG neurons. Paclitaxel caused a depolarization of DRG neurons with a decrease in resting membrane potential, suggesting an associated opening of "leak" potassium currents and HCN channels. Hyperpolarization-activated cation currents ( $\mathrm{HCN}$ channels) contribute to a wide range of physiological functions, including cardiac and neuronal pacemaker activity (automaticity), the setting of resting membrane potential, and control action potential firing (Robinson and Siegelbaum, 2003). The decrease in action potential rising time and increase in time of action potential falling time suggest the modulation of voltage-gated sodium, potassium, and calcium channels.

The downstream signaling pathways engaged by TLR4 to sensitize TRPV1 remain to be determined. The data presented here would suggest that at least two such pathways are en- 
gaged: a short-term, fast acting pathway and a slower, longacting pathway (Ji et al., 2009). Paclitaxel activated DRG neurons directly and increased the number of evoked action potentials and this was in the context of also altering the shape of the evoked action potentials. In the spinal cord, paclitaxel had a direct acute effect in increasing the frequency of mEPSCs, but no acute effect on sEPSCs. This suggests that paclitaxel interacts with presynaptic terminals in the dorsal horn, but not directly onto other spinal neurons. Conversely, DRG and spinal neurons also showed persistent changes in TRPV1-mediated activity such as increased spinal neuron sEPSCs that were present long after paclitaxel would have been eliminated. TLR4 signaling similarly includes two distinct elements, the canonical Myeloid-differentiation response gene 88 (MyD88) and TRIF and noncanonical MAPK pathways. TLR4 signaling in the DRG and the spinal cord was shown previously to contribute to the induction and maintenance of paclitaxel-related CIPN (Li et al., 2014b). Paclitaxel treatment resulted in increased expression of TLR4, as well as MyD88 and TRIF, in DRG neurons that paralleled the development of chemotherapy-related mechanical hyperresponsiveness (Li et al., 2014b). Moreover, cotreatment of rats with the TLR4 antagonist LPS-RS during chemotherapy prevented the upregulation of TLR4, MyD88, and TRIF, as well as the development of the behavioral CIPN phenotype (Li et al., 2014b). However, in addition to MyD88 and TRIF, MAPKs are also activated downstream of TLR4 and the activation of MAPKs in sensory neurons also contributed to behavioral hypersensitivity after nerve injury (Li et al., 2014b). Recently, inhibitors of the TLR4 noncanonical MAPK signal pathways have been shown to partially prevent paclitaxel CIPN (Li et al., 2015).

Activation of canonical TLR signaling leads to its widely recognized proinflammatory responses. Similarly, paclitaxel activates TLR4 in monocytes, resulting in the activation of the canonical path leading to activation of NF- $\kappa \mathrm{B}$ that leads to the induction and release of proinflammatory cytokine expression identical to that produced by LPS (Han et al., 1994; Karin and Ben-Neriah, 2000; Byrd-Leifer et al., 2001; Li et al., 2013). Specifically, the cytokines IFN $\alpha / \gamma$, TNF $\alpha$, IL-1, and IL- 6 are increased in vitro by paclitaxel (O'Brien et al., 1995; Zaks-Zilberman et al., 2001) and cisplatin (Pai and Sodhi, 1991; Basu and Sodhi, 1992; Gan et al., 1992). The sustained activity of these proinflammatory cytokines could well underlie the more chronic responses of DRG and spinal neurons observed here. For example, IL- $1 \beta$ was shown to activate voltage-gated calcium channels and to inhibit voltagegated sodium channels (Zhang et al., 2008; Zhou et al., 2011). Conversely, TNF- $\alpha$ upregulates the voltage-gated sodium channels Nav1.3 and Nav1.8 (He et al., 2010). IL-1 $\beta$ can activate the NMDA receptor directly and enhance excitatory synaptic transmission (Vezzani et al., 1999). TNF- $\alpha$ enhances the frequency of sEPSCs directly in spinal neurons (Kawasaki et al., 2008; Zhang et al., 2010) and leads to increased sensitivity of TRPV1 receptors (Spicarova and Palecek, 2010). LPS induces a rapid glutamate release in rat cortex slices and results in increased excitability of cortical neurons (Rodgers et al., 2009). LPS inhibits glutamate reuptake by astrocytes and enhances astrocytes' glutamate release (Ye and Sontheimer, 1996).

Although possibly contributing to more sustained changes in DRG and spinal neurons, the TLR4-MyD88-NF $\mathrm{B}$ process takes several hours, whereas other data shown here clearly demonstrated an acute interaction between paclitaxel (or LPS) and TLR4, resulting in increased excitability of human and rat peripheral sensory neurons, HEK293 cells, and mouse spinal neu- rons within several minutes. These data are better explained by hypothesizing engagement of the noncanonical TLR4 MAPK signal pathways. As noted above, previous experiments showed that paclitaxel treatment engages the signaling of ERK1/2 and p38 through TLR4. MAPK activation has also been shown to modulate the activities of ion channels such as sodium channel Nav1.7 and TRPV1 (Ji et al., 2002; Han et al., 2013), which have also been implicated as contributing to paclitaxel-related CIPN (Hara et al., 2013; Zhang and Dougherty, 2014). Another important consideration is that p38 and ERK1/2 integrate the activities of protein kinase signaling in DRG and spinal neurons ( $\mathrm{Hu}$ and Gereau, 2003; Jin and Gereau, 2006; Han et al., 2012) and protein kinase C is a well defined pathway for regulation of TRPV1 signaling, including reversal of TRPV1 desensitization (Bhave et al., 2003; Han et al., 2012). PKC $\varepsilon$ is also a component of TLR4 signaling that plays a key role in macrophage and dendritic cell activation in response to LPS (Aksoy et al., 2004). PKC $\varepsilon$ is expressed in nociceptors and also has important roles in pain signaling (Numazaki et al., 2002; Vellani et al., 2004).

An important caveat to be considered is that, although an agonist effect of paclitaxel on TLR4 in rodents is widely accepted (Ding et al., 1990; Fitzpatrick and Wheeler, 2003; Javeed et al., 2009), such an effect for paclitaxel on human TLR4 is controversial. Some studies have reported pronounced cytokine production from human macrophages and other tissues by paclitaxel (Hashiguchi et al., 1982; White et al., 1998; Cassidy et al., 2002; Wang et al., 2002), whereas others have not observed this (Manthey et al., 1993; Zimmer et al., 2008). TLR4 requires the accessory protein MD-2 for binding and activation by LPS and paclitaxel in murine macrophages (Fitzpatrick and Wheeler, 2003; Javeed et al., 2009). MD-2 is also required for activation of macrophages in humans by LPS, but it has been reported that paclitaxel binds MD-2 in a fashion that precludes activation of TLR4 (Kawasaki et al., 2001; Resman et al., 2008; Zimmer et al., 2008). It is difficult to reconcile this discrepancy, which has importance in the context here concerning the mechanisms of CIPN but, in a broader scope, concerning the utility of paclitaxel as a chemotherapeutic. A number of recent studies show a clear link between chemoresistance and even the promotion of aggressiveness in many human cancer types by paclitaxel when TLR4 is expressed in these tissues (Szajnik et al., 2009; Geller et al., 2010; Volk-Draper et al., 2014). A possible explanation may be that an interaction between paclitaxel's binding to microtubules enhances its signaling via TLR4 (Fitzpatrick and Wheeler, 2003). This mechanism would clearly have a strong basis in DRG neurons and perhaps also those tumors expressing TLR4.

In summary, paclitaxel CIPN is shown here to involve a TLR4-TRPV1 mechanism that itself appears to be mediated by both an acute and a longer term sensitization of TRPV1 by TLR4. This interaction is shown to be present in rat, mouse and human sensory neurons and the acute interaction can be replicated in HEK293 cells expressing human TLR4 and TRPV1. The specific second messenger pathways that are engaged in this interaction and how this mechanism relates to the clinical stocking-andglove distribution of CIPN remain to be fully defined. It would appear that these answers should reveal a rich substrate for the development of new potential therapeutics for the prevention or treatment of CIPN and could lead to important new insights to the basic mechanisms of neuropathic pain.

\section{References}

Agalave NM, Larsson M, Abdelmoaty S, Su J, Baharpoor A, Lundbäck P, Palmblad K, Andersson U, Harris H, Svensson CI (2014) Spinal 
HMGB1 induces TLR4-mediated long-lasting hypersensitivity and glial activation and regulates pain-like behavior in experimental arthritis. Pain 155:1802-1813. CrossRef Medline

Aksoy E, Goldman M, Willems F (2004) Protein kinase C epsilon: a new target to control inflammation and immune-mediated disorders. Int J Biochem Cell Biol 36:183-188. CrossRef Medline

Basu S, Sodhi A (1992) Increased release of interleukin-1 and tumour necrosis factor by interleukin-2-induced lymphokine-activated killer cells in the presence of cisplatin and FK-565. Immunol Cell Biol 70:15-24. CrossRef Medline

Bhave G, Hu HJ, Glauner KS, Zhu W, Wang H, Brasier DJ, Oxford GS, Gereau RW 4th (2003) Protein kinase C phosphorylation sensitizes but does not activate the capsaicin receptor transient receptor potential vanilloid 1 (TRPV1). Proc Natl Acad Sci U S A 100:12480-12485. CrossRef Medline

Boyette-Davis J, Dougherty PM (2011) Protection against oxaliplatininduced mechanical hyperalgesia and intraepidermal nerve fiber loss by minocycline. Exp Neurol 229:353-357. CrossRef Medline

Boyette-Davis JA, Cata JP, Zhang H, Driver LC, Wendelschafer-Crabb G, Kennedy WR, Dougherty PM (2011b) Follow-up psychophysical studies in bortezomib-related chemoneuropathy patients. J Pain 12:10171024. CrossRef Medline

Boyette-Davis JA, Cata JP, Driver LC, Novy DM, Bruel BM, Mooring DL, Wendelschafer-Crabb G, Kennedy WR, Dougherty PM (2013) Persistent chemoneuropathy in patients receiving the plant alkaloids paclitaxel and vincristine. Cancer Chemother Pharmacol 71:619-626. CrossRef Medline

Boyette-Davis J, Xin W, Zhang H, Dougherty PM (2011a) Intraepidermal nerve fiber loss corresponds to the development of Taxol-induced hyperalgesia and can be prevented by treatment with minocycline. Pain 152: 308-313. CrossRef Medline

Byrd-Leifer CA, Block EF, Takeda K, Akira S, Ding A (2001) The role of MyD88 and TLR4 in the LPS-mimetic activity of taxol. Eur J Immunol 31:2448-2457. CrossRef Medline

Cassidy PB, Moos PJ, Kelly RC, Fitzpatrick FA (2002) Cyclooxygenase-2 induction by paclitaxel, docetaxel and taxane analogs in human monocytes and mruine macrophages: structure-activity relationships and their implications. Clin Cancer Res 8:846-855. Medline

Chaplan SR, Bach FW, Pogrel JW, Chung JM, Yaksh TL (1994) Quantitative assessment of tactile allodynia in the rat paw. J Neurosci Methods 53: 55-63. CrossRef Medline

Chaudhry V, Rowinsky EK, Sartorius SE, Donehower RC, Cornblath DR (1994) Peripheral neuropathy from taxol and cisplatin combination chemotherapy: clinical and electrophysiological studies. Ann Neurol 35:304311. CrossRef Medline

Christianson CA, Dumlao DS, Stokes JA, Dennis EA, Svensson CI, Corr M, Yaksh TL (2011) Spinal TLR4 mediates the transition to a persistent mechanical hypersensitivity after the resolution of inflammation in serum-transferred arthritis. Pain 152:2881-2891. CrossRef Medline

Davidson S, Copits BA, Zhang J, Page G, Ghetti A, Gereau RW 4th (2014) Human sensory neurons: Membrane properties and sensitization by inflammatory mediators. Pain 155:1861-1870. CrossRef Medline

Ding AH, Porteu F, Sanchez E, Nathan CF (1990) Shared actions of endotoxin and taxol on TNF receptors and TNF release. Science 248:370-372. CrossRef Medline

Diogenes A, Ferraz CC, Akopian AN, Henry MA, Hargreaves KM (2011) LPS sensitizes TRPV1 via activation of TLR4 in trigeminal sensory neurons. J Dent Res 90:759-764. CrossRef Medline

Fitzpatrick FA, Wheeler R (2003) The immunopharmacology of paclitaxel $\left(\right.$ Taxol $\left.^{\circledR}\right)$ docetaxel (Taxotere ${ }^{\circledR}$ ), and related agents. Int Immunopharmacol 3:1699-1714. CrossRef Medline

Gan XH, Jewett A, Bonavida B (1992) Activation of human peripheralblood-derived monocytes by cis- diamminedichloroplatinum: enhanced tumoricidal activity and secretion of tumor necrosis factor-alpha. Nat Immun 11:144-155. Medline

Gavva NR, Tamir R, Qu Y, Klionsky L, Zhang TJ, Immke D, Wang J, Zhu D, Vanderah TW, Porreca F, Doherty EM, Norman MH, Wild KD, Bannon AW, Louis JC, Treanor JJ (2005) AMG 9810 [(E)-3-(4-t-butylphenyl)$\mathrm{N}$-(2,3-dihydrobenzo[b] [1,4] dioxin-6 yl)acrylamide], a novel vanilloid receptor 1 (TRPV1) antagonist with antihyperalgesic properties. J Pharmacol Exp Ther 313:474-484. Medline

Geller MA, Bui-Nguyen TM, Rogers LM, Ramakrishnan S (2010) Chemo- therapy induces macrophage chemoattractant protein-1 production in ovarian cancer. Int J Gynecol Cancer 20:918-925. CrossRef Medline

Hagiwara H, Sunada Y (2004) Mechanism of taxane neurotoxicity. Breast Cancer 11:82-85. CrossRef Medline

Han J, Lee JD, Bibbs L, Ulevitch RJ (1994) A MAP kinase targeted by endotoxin and hyperosmolality in mammalian cells. Science 265:808-811. CrossRef Medline

Han L, Ma C, Liu Q, Weng HJ, Cui Y, Tang Z, Kim Y, Nie H, Qu L, Patel KN, Li Z, McNeil B, He S, Guan Y, Xiao B, Lamotte RH, Dong X (2013) A subpopulation of nociceptors specifically linked to itch. Nat Neurosci 16:174-182. CrossRef Medline

Han Y, Li Y, Xiao X, Liu J, Meng XL, Liu FY, Xing GG, Wan Y (2012) Formaldehyde up-regulates TRPV1 through MAPK and PI3K signaling pathways in a rat model of bone cancer pain. Neurosci Bull 28:165-172. CrossRef Medline

Hara T, Chiba T, Abe K, Makabe A, Ikeno S, Kawakami K, Utsunomiya I, Hama T, Taguchi K (2013) Effect of paclitaxel on transient receptor potential vallinoid 1 in rat dorsal root ganglion. Pain 154:882-889. CrossRef Medline

Hashiguchi T, Kobayashi H, Tosaka T, Libet B (1982) Two muscarinic depolarizing mechanisms in mammalian sympathetic neurons. Brain Res 242:378-382. CrossRef Medline

He XH, Zang Y, Chen X, Pang RP, Xu JT, Zhou X, Wei XH, Li YY, Xin WJ, Qin ZH, Liu XG (2010) TNF-alpha contributes to up-regulation of Nav1.3 and Nav1.8 in DRG neurons following motor fiber injury. Pain 151:266279. CrossRef Medline

Hu HJ, Gereau RW 4th (2003) ERK integrates PKA and PKC signaling in superficial dorsal horn neurons. II. Modulation of neuronal excitability. J Neurophysiol 90:1680-1688. CrossRef Medline

Javeed A, Ashraf M, Riaz A, Ghafoor A, Afzal S, Mukhtar MM (2009) Paclitaxel and the immune system. Eur J Pharm Sci 38:283-290. CrossRef Medline

Ji RR, Samad TA, Jin SX, Schmoll R, Woolf CJ (2002) p38 MAPK activation by NGF in primary sensory neurons after inflammation increases TRPV1 levels and maintains heat hyperalgesia. Neuron 36:57-68. CrossRef Medline

Ji RR, Gereau RW 4th, Malcangio M, Strichartz GR (2009) MAP kinase and pain. Brain Res Rev 60:135-148. CrossRef Medline

Jin X, Gereau RW 4th (2006) Acute p38-mediated modulation of tetrodotoxin-resistant sodium channels in mouse sensory neurons by tumor necrosis factor-alpha. J Neurosci 26:246-255. CrossRef Medline

Karin M, Ben-Neriah Y (2000) Phosphorylation meets ubiquitination: the control of NF-kB activity. Annu Rev Immunol 18:621-663. CrossRef Medline

Kawasaki K, Gomi K, Nishijima M (2001) Cutting edge:Gln ${ }^{22}$ of mouse MD-2 is essential for species-specific lipolysaccharide mimetic action of taxol. J Immunol 166:11-14. CrossRef Medline

Kawasaki Y, Zhang L, Cheng JK, Ji RR (2008) Cytokine mechanisms of central sensitization: distinct and overlapping role of interleukin-1beta, interleukin-6, and tumor necrosis factor-alpha in regulating synaptic and neuronal activity in the superficial spinal cord. J Neurosci 28:5189-5194. CrossRef Medline

Kosturakis AK, He Z, Li Y, Boyette-Davis JA, Shah N, Thomas SK, Zhang H, Vichaya EG, Wang XS, Wendelschafer-Crabb G, Kennedy WR, Simone DA, Cleeland CS, Dougherty PM (2014) Subclinical peripheral neuropathy in patients with multiple myeloma before chemotherapy is correlated with decreased fingertip innervation density. J Clin Oncol 32:3156-3162. CrossRef Medline

Li D, Fu Y, Zhang W, Su G, Liu B, Guo M, Li F, Liang D, Liu Z, Zhang X, Cao Y, Zhang N, Yang Z (2013) Salidroside attenuates inflammatory responses by suppressing nuclear factor-kappaB and mitogen activated protein kinases activation in lipopolysaccharide-induced mastitis in mice. Inflamm Res 62:9-15. CrossRef Medline

Lian H, Sun J, Zhang T (2013) A rapid and sensitive determination of paclitaxel in rat plasma by UPLC-MS/MS method: application to a pharmacokinetic study. Asian J Pharm Sci 8:199-205. CrossRef

Li Y, Cai J, Han Y, Xiao X, Meng XL, Su L, Liu FY, Xing GG, Wan Y (2014a) Enhanced function of TRPV1 via up-regulation by insulin-like growth factor-1 in a rat model of bone cancer pain. Eur J Pain 18:774-784. CrossRef Medline

Li Y, Zhang H, Zhang H, Kosturakis AK, Jawad AB, Dougherty PM (2014b) 
Toll-like receptor 4 signaling contributes to paclitaxel-induced peripheral neuropathy. J Pain 15:712-725. Medline

Li Y, Zhang H, Kosturakis AK, Cassidy RM, Zhang H, Kennamer-Chapman RM, Jawad AB, Colomand CM, Harrison DS, Dougherty PM (2015) MAPK signaling downstream to TLR4 contributes to paclitaxel-induced peripheral neuropathy. Brain Behav Immun 49:255-266. CrossRef Medline

Liu T, Xu ZZ, Park CK, Berta T, Ji RR (2010) Toll-like receptor 7 mediates pruritus. Nat Neurosci 13:1460-1462. CrossRef Medline

Liu T, Berta T, Xu ZZ, Park CK, Zhang L, Lü N, Liu Q, Liu Y, Gao YJ, Liu YC, Ma Q, Dong X, Ji RR (2012) TLR3 deficiency impairs spinal cord synaptic transmission, central sensitization, and pruritus in mice. J Clin Invest 122:2195-2207. CrossRef Medline

Manthey CL, Qureshi N, Stütz PL, Vogel SN (1993) Lipopolysaccharide antagonists block taxol-induced signaling in murine macrophages. J Exp Med 178:695-702. CrossRef Medline

Marchettini P, Simone DA, Caputi G, Ochoa JL (1996) Pain from excitation of identified muscle nociceptors in humans. Brain Res 740:109-116. CrossRef Medline

Nagy I, Friston D, Valente JS, Torres Perez JV, Andreou AP (2014) Pharmacology of the capsaicin receptor, transient receptor potential vanilloid type-1 ion channel. Prog Drug Res 68:39-76. Medline

Numazaki M, Tominaga T, Toyooka H, Tominaga M (2002) Direct phosphorylation of capsaicin receptor VR1 by protein kinase Cepsilon and identification of two target serine residues. J Biol Chem 277:13375-13378. CrossRef Medline

O'Brien JM Jr, Wewers MD, Moore SA, Allen JN (1995) Taxol and colchicine increase LPS-induced pro-IL-1 beta production, but do not increase IL-1 beta secretion: a role for microtubules in the regulation of IL-1 beta production. J Immunol 154:4113-4122. Medline

Ochoa-Cortes F, Ramos-Lomas T, Miranda-Morales M, Spreadbury I, Ibeakanma C, Barajas-Lopez C, Vanner S (2010) Bacterial cell products signal to mouse colonic nociceptive dorsal root ganglia neurons. Am J Physiol Gastrointest Liver Physiol 299:G723-G732. CrossRef Medline

Pai K, Sodhi A (1991) Effect of cisplatin, rIFN-Y, LPS and MDP on release of $\mathrm{H} 2 \mathrm{O} 2$, O2- and lysozyme from human monocytes in vitro. Indian J Exp Biol 29:910-915. Medline

Polomano RC, Mannes AJ, Clark US, Bennett GJ (2001) A painful peripheral neuropathy in the rat produced by the chemotherapeutic drug, paclitaxel. Pain 94:293-304. CrossRef Medline

Reeves BN, Dakhil SR, Sloan JA, Wolf SL, Burger KN, Kamal A, LeLindqwister NA, Soori GS, Jaslowski AJ, Kelaghan J, Novotny PJ, Lachance DH, Loprinzi CL (2012) Further data supporting that paclitaxel-associated acute pain syndrome is associated with development of peripheral neuropathy: North Central Cancer Treatment Group trial N08C1. Cancer 118:5171-5178. CrossRef Medline

Resman N, Gradisar H, Vasl J, Keber MM, Pristovsek P, Jerala R (2008) Taxanes inhibit human TLR4 signaling by binding to MD-2. FEBS Lett 582:3929-3934. CrossRef Medline

Robinson RB, Siegelbaum SA (2003) Hyperpolarization-activated cation currents: from molecules to physiological function. Annu Rev Physiol 65:453-480. CrossRef Medline

Rodgers KM, Hutchinson MR, Northcutt A, Maier SF, Watkins LR, Barth DS (2009) The cortical innate immune response increases local neuronal excitability leading to seizures. Brain 132:2478-2486. CrossRef Medline

Sałat K, Filipek B (2015) Antinociceptive activity of transient receptor potential channel TRPV1, TRPA1, and TRPM8 antagonists in neurogenic and neuropathic pain models in mice. J Zhejiang Univ Sci B 16:167-178. CrossRef Medline

Simone DA, Baumann TK, LaMotte RH (1989) Dose-dependent pain and mechanical hyperalgesia in humans after intradermal injection of capsaicin. Pain 38:99-107. CrossRef Medline

Spicarova D, Palecek J (2010) Tumor necrosis factor alpha sensitizes spinal cord TRPV1 receptors to the endogenous agonist $\mathrm{N}$-oleoyldopamine. J Neuroinflammation 7:49. CrossRef Medline

Stokes JA, Cheung J, Eddinger K, Corr M, Yaksh TL (2013) Toll-like receptor signaling adapter proteins govern spread of neuropathic pain and recovery following nerve injury in male mice. J Neuroinflammation 10: 148. CrossRef Medline

Szajnik M, Szczepanski MJ, Czystowska M, Elishaev E, Mandapathil M,
Nowak-Markwitz E, Spaczynski M, Whiteside TL (2009) TLR4 signaling induced by lipopolysaccharide or paclitaxel regulates tumor survival and chemoresistance in ovarian cancer. Oncogene 28:4353-4363. CrossRef Medline

Vellani V, Zachrisson O, McNaughton PA (2004) Functional bradykinin B1 receptors are expressed in nociceptive neurones and are upregulated by the neurotrophin GDNF. J Physiol 560:391-401. CrossRef Medline

Vezzani A, Conti M, De Luigi A, Ravizza T, Moneta D, Marchesi F, De Simoni MG (1999) Interleukin-lbeta immunoreactivity and microglia are enhanced in the rat hippocampus by focal kainate application: functional evidence for enhancement of electrographic seizures. J Neurosci 19:50545065. Medline

Volk-Draper L, Hall K, Griggs C, Rajput S, Kohio P, DeNardo D, Ran S (2014) Paclitaxel therapy promotes breast cancer metastasis in a TLR4dependent manner. Cancer Res 74:5421-5434. Medline

Wang J, Kobayashi M, Han M, Choi S, Takano M, Hashino S, Tanaka J, Kondoh T, Kawamura K, Hosokawa M (2002) MyD88 is involved in the signalling pathway for Taxol-induced apoptosis and TNF-a expression in human myelomonocytic cells. Br J Haematol 118:638-645. CrossRef Medline

White CM, Martin BK, Lee LF, Haskill JS, Ting JP (1998) Effects of paclitaxel on cytokine synthesis by unprimed human monocytes, T lymphocytes, and breast cancer cells. Cancer Immunol Immunother 46:104-112. CrossRef Medline

Witting N, Svensson P, Gottrup H, Arendt-Nielsen L, Jensen TS (2000) Intramuscular and intradermal injection of capsaicin: a comparison of local and referred pain. Pain 84:407-412. CrossRef Medline

Xiao WH, Zheng H, Zheng FY, Nuydens R, Meert TF, Bennett GJ (2011) Mitochondrial abnormality in sensory, but not motor, axons in paclitaxel-evoked painful peripheral neuropathy in the rat. Neuroscience 199:461-469. CrossRef Medline

Ye ZC, Sontheimer H (1996) Cytokine modulation of glial glutamate uptake: a possible involvement of nitric oxide. Neuroreport 7:2181-2185. CrossRef Medline

Yu L, Yang F, Luo H, Liu FY, Han JS, Xing GG, Wan Y (2008) The role of TRPV1 in different subtypes of dorsal root ganglion neurons in rat chronic inflammatory nociception induced by complete Freund's adjuvant. Mol Pain 4:61. CrossRef Medline

Zaks-Zilberman M, Zaks TZ, Vogel SN (2001) Induction of proinflammatory and chemokine genes by lipopolysaccharide and paclitaxel (Taxol) in murine and human breast cancer cell lines. Cytokine 15:156-165. CrossRef Medline

Zhang H, Dougherty PM (2014) Enhanced excitability of primary sensory neurons and altered gene expression of neuronal ion channels in dorsal root ganglion in paclitaxel-induced peripheral neuropathy. Anesthesiology 120:1463-1475. CrossRef Medline

Zhang H, Nei H, Dougherty PM (2010) A p38 mitogen-activated protein kinase-dependent mechanism of disinhibition in spinal synaptic transmission induced by tumor necrosis factor-alpha. J Neurosci 30:1284412855. CrossRef Medline

Zhang H, Boyette-Davis JA, Kosturakis AK, Li Y, Yoon SY, Walters ET, Dougherty PM (2013a) Induction of monocyte chemoattractant protein-1 (MCP-1) and its receptor CCR2 in primary sensory neurons contributes to paclitaxel-induced peripheral neuropathy. J Pain 14:10311044. CrossRef Medline

Zhang H, Zhang H, Dougherty PM (2013b) Dynamic effects of TNF-alpha on synaptic transmission in mice over time following sciatic nerve chronic constriction injury. J Neurophysiol 110:1663-1671. CrossRef Medline

Zhang R, Yamada J, Hayashi Y, Wu Z, Koyama S, Nakanishi H (2008) Inhibition of NMDA-induced outward currents by interleukin-1beta in hippocampal neurons. Biochem Biophys Res Commun 372:816-820. CrossRef Medline

Zhou C, Qi C, Zhao J, Wang F, Zhang W, Li C, Jing J, Kang X, Chai Z (2011) Interleukin-1beta inhibits voltage-gated sodium currents in a time- and dose-dependent manner in cortical neurons. Neurochem Res 36:11161123. CrossRef Medline

Zimmer SM, Liu J, Clayton JL, Stephens DS, Snyder JP (2008) Paclitaxel binding to human and murine MD-2. J Biol Chem 283:27916-27926. CrossRef Medline 